\title{
8
}
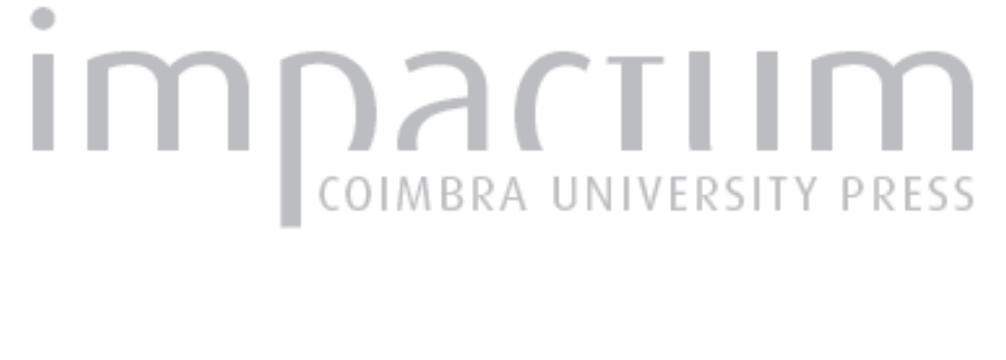

Um contexto e um lugar para os discos de ouro da I Idade do Ferro de Fortios (Portalegre, Alto Alentejo, Portugal) \author{
$\begin{array}{ll}\text { Autor(es): } & \text { Vilaça, Raquel; Armbruster, Barbara; Perea, Alicia; Vivas, Fábio; Freitas, } \\ \text { Bruno }\end{array}$ \\ Publicado por: Faculdade de Letras da Universidade de Coimbra \\ URL \\ persistente: \\ URI:http://hdl.handle.net/10316.2/38792 \\ DOI: \\ DOI:http://dx.doi.org/10.14195/1647-8657_53_2 \\ Accessed : $\quad$ 26-Apr-2023 15:42:56
}

A navegação consulta e descarregamento dos títulos inseridos nas Bibliotecas Digitais UC Digitalis, UC Pombalina e UC Impactum, pressupõem a aceitação plena e sem reservas dos Termos e Condições de Uso destas Bibliotecas Digitais, disponíveis em https://digitalis.uc.pt/pt-pt/termos.

Conforme exposto nos referidos Termos e Condições de Uso, o descarregamento de títulos de acesso restrito requer uma licença válida de autorização devendo o utilizador aceder ao(s) documento(s) a partir de um endereço de IP da instituição detentora da supramencionada licença.

Ao utilizador é apenas permitido o descarregamento para uso pessoal, pelo que o emprego do(s) título(s) descarregado(s) para outro fim, designadamente comercial, carece de autorização do respetivo autor ou editor da obra.

Na medida em que todas as obras da UC Digitalis se encontram protegidas pelo Código do Direito de Autor e Direitos Conexos e demais legislação aplicável, toda a cópia, parcial ou total, deste documento, nos casos em que é legalmente admitida, deverá conter ou fazer-se acompanhar por este aviso. 
CONIMBRIGA

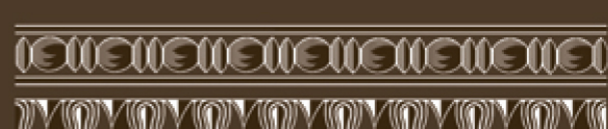

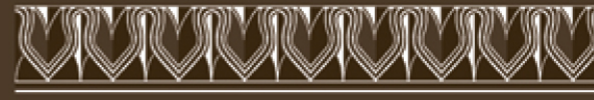

INSTITUTO DE ARQUEOLOGIA

VOLUME LIII • 2014

FACULDADE DE LETRAS 
RAQUEL VILAÇA

Instituto de Arqueologia. Faculdade de Letras da Universidade de Coimbra.

CEAACP-FCT

rvilaca@fl.uc.pt

Barbara Armbruster

Universidade de Toulouse. CNRS-UMR 5608

barbara.armbruster@univ.-tlse2.fr

Alicia Perea

Grupo de Investigación Arqueometal. Instituto de Historia, CSIC

alicia.perea@cchc.csic.es

FÁBIO VIVAS

Mestrando em Arqueologia e Território.

Faculdade de Letras da Universidade de Coimbra

fabio_vivas77@hotmail.com

BRUNO FREITAS

Mestrando em Arqueologia e Território.

Faculdade de Letras da Universidade de Coimbra

brunoremo1@msn.com

UM CONTEXTO E UM LUGAR PARA OS DISCOS DE OURO

DA I IDADE DO FERRO DE FORTIOS

(PORTALEGRE, ALTO ALENTEJO, PORTUGAL)

A CONTEXT AND A PLACE FOR THE GOLD DISKS

FROM THE EARLY IRON AGE OF FORTIOS

(PORTALEGRE, ALTO ALENTEJO, PORTUGAL)

"Conimbriga" LIII (2014) p. 31-79

http://dx.doi.org/10.14195/1647-8657_53_2

Conimbriga, 53 (2014) 31-79 
Resumo: Conhecido desde finais dos anos trinta do séc. XX, o designado "tesouro de Fortios", constituído originalmente por oitenta e oito discos de ouro de que se localizaram sessenta e oito, todos iguais, é estudado numa perspectiva que atende a diversas problemáticas: historiográfica, contextual, tipológica, tecnológica, funcional, cronológica, cultural e simbólica. Apoiando-se em documentação inédita ou pouco valorizada, completada com trabalho de campo, os autores identificam o local e contexto de achado (em recipiente cerâmico) deste depósito, que é possível associar a lugar em altura de provável cariz habitacional. Tal como outros discos com os quais se compara, o conjunto é atribuído aos inícios da Idade do Ferro, revelando a nível tecnológico e estilístico uma nova forma de fabrico com produções em série, economia de tempo, uso da filigrana e da solda. Acredita-se que estas delicadas peças seriam aplicadas sobre vestuário de prestígio e, por ventura, também sagrado, de elevado valor conotado com a simbologia solar.

PalaVRas-ChaVE: discos; ourivesaria; I Idade do Ferro; depósito; Alentejo (Portugal)

ABstRACT: Having been known since the late thirties of the twentieth century, the so called "treasure of Fortios", originally comprised of eighty-eight gold disks of which sixty-eight have been localized, every one identical, is studied in a perspective that addresses a variety of issues: historiographical, context related, typological, technological, functional, chronological, cultural and symbolic. Supported by yet unpublished or undervalued documentation, and complemented with field study, the authors identified the place and context of the find (in a ceramic container) belonging to this hoard, which can be associated to a high place of a probably habitational nature. Just as with the other comparable disks, the set is assigned to the Early Iron Age, revealing on a technological and stylistic level a new process of manufacture with mass production, the economization of time, and the use of filigree and soldering. It is believed that these delicate pieces were applied over prestigious and perhaps sacred clothing, of high value and related to solar symbolism.

KEYWORDS: gold discoid appliqués; early iron age; hoard; Alentejo (Portugal) 


\section{UM CONTEXTO E UM LUGAR PARA OS DISCOS DE OURO DA I IDADE DO FERRO DE FORTIOS (PORTALEGRE, ALTO ALENTEJO, PORTUGAL)}

\section{Introdução}

A colecção arqueológica do Instituto de Arqueologia da Faculdade de Letras da Universidade de Coimbra ${ }^{1}$ possui quinze discos de ouro pertencentes ao designado "Tesouro de Fortios" (Portalegre), em tudo semelhantes aos que se encontram expostos na "Sala do Tesouro" do Museu Nacional de Arqueologia (Lisboa), com a mesma proveniência.

Este notável achado, ocorrido por mero acaso nos finais da década de trinta do século XX, era originalmente composto pelo impressionante número de oitenta e oito (ou oitenta e cinco) discos (por vezes designados como botões), consoante as fontes (REIs 1938; AzEREDo 1980), que se dispersaram por diversas mãos pouco tempo depois.

Ao contrário dos discos do Museu Nacional de Arqueologia, conhecidos do público e referidos em diversas publicações no âmbito de sínteses, inventários ou catálogos de exposições, os de Coimbra encontram-se inéditos, embora tenham figurado temporariamente em exposição no Museu Municipal Dr. Santos Rocha (Figueira da Foz), de que se faz eco em curtíssima anotação no respectivo catálogo (PEREIRA 1994: 69).

Por este motivo e pelas facilidades de acesso às peças, bem como pela enorme importância do "tesouro" em si, considerou-se ser muito oportuno dedicar especial atenção à sua análise e divulgação, objectivo

${ }^{1}$ Hoje integrado, desde a departamentalização da Faculdade de Letras em 2008, na Secção de Arqueologia do Departamento de História, Estudos Europeus, Arqueologia e Artes daquela Faculdade.

Conimbriga, 53 (2014) 31-79 
imediato deste trabalho ${ }^{2}$. Ao mesmo tempo, esse estudo só faria sentido numa perspectiva integradora do conjunto, que o inquirisse atendendo à sua natureza de achado - um depósito - provido necessariamente de alguma contextualização, fosse ela qual fosse, objectivo que acompanhou aquele e que foi atingido de forma muito satisfatória.

$\mathrm{Na}$ verdade, e não obstante este depósito reunir o maior conjunto de aplicações áureas pré-históricas conhecidas na Península Ibérica ${ }^{3}$, todas completas e em muito bom estado de conservação, nunca mereceu uma necessária abordagem global de cariz monográfico, visando as diversas problemáticas específicas, sejam de natureza historiográfica, contextual, tipológica, tecnológica, funcional, cronológica, cultural e simbólica.

Pela conjugação de diversos esforços, pessoas e instituições, é agora possível dar alguns passos nesse sentido. A apresentação pública do achado fez-se recentemente (Março de 2015) no Colóquio Internacional L'Or de l'âge du Fer en Europe celtique. Société, technologie et archéometrie, realizado em Toulouse (VILAÇA et al. no prelo), no qual se valorizaram, sobretudo, os aspectos a nível tipológico, tecnológico e interpretativo. Mas divulgaram-se também os resultados preliminares da análise arqueométrica, que merecerá estudo específico (Perea et al. no prelo), e atendeu-se ainda às informações documentais existentes, insuficientemente ou nunca exploradas, vertente que agora aprofundamos, como notícias na imprensa diária e correspondência epistolar, as quais ajudam a compreender a contextualização arqueológica deste depósito, cujo local de achado foi igualmente identificado.

\section{A descoberta e o que mais se seguiu...}

Por circunstâncias várias e comuns a inúmeras situações conhecidas, o achado casual de artefactos em ouro arrasta sempre problemas de diversa ordem. Um deles é o descaminho que muitas das peças levam. Numa breve pesquisa bibliográfica relativa só à situação portuguesa,

${ }^{2}$ Investigação desenvolvida no âmbito do projecto "Questionando o Bronze e o Ouro: produção e deposição do metal na Idade do Bronze do Ocidente Peninsular", apoiado financeiramente pela Fundação Calouste Gulbenkian, a quem se agradece.

${ }^{3}$ Apenas num outro caso foi registado o número de pelo menos setenta e três pequenos cones de ouro da Idade do Bronze (El Argar) (Perea 1991: 89; López PADILla 2006).

Conimbriga, 53 (2014) 31-79 
foi fácil elencar cerca de quarenta achados ocorridos durante os últimos 150 anos cujas peças foram destruídas e roubadas, se dispersaram ou desapareceram (VILAÇA 2013).

No caso dos discos atribuídos a Fortios, encontrados durante trabalhos agrícolas, houve também destruição, dispersão e desaparecimento, mas estes constrangimentos, se bem que limitadores, foram insuficientes para comprometer a memória relativa ao achado, suas circunstâncias e estudo do conjunto.

O que se sabe?

Pelos anos de 1935-36 (Bernardo 2002: 37), quando um grupo de trabalhadores lavrava a terra numa propriedade perto de Fortios, um dos bois partiu com uma das patas um púcaro de barro de onde saíram as peças. A descoberta logo se espalhou e dela viria a ser dada notícia num dos jornais diários de maior circulação à época, o Diário de Notícias, com o título "Um tesouro de há 3.000 anos foi achado perto de Portalegre" (ReIs 1938) (FIG. 1).

São de grande importância as informações então recolhidas, as quais, cotejadas com outros dados (Heleno 1939; FerReIRA 1974; AzEREDO 1980; BERNARDO 2002), permitem reconstituir, não obstante algumas discrepâncias, uma aproximação ao histórico deste conjunto, nomeadamente no que se refere à proveniência, natureza do sítio, circunstâncias em que foi encontrado e destino das peças.

Dispomos de duas versões mais circunstanciadas do achado, ambas resultantes de entrevistas realizadas, num caso ao próprio trabalhador que encontrou os discos, José Casquinha (AzEREDo 1980), noutro caso a um outro trabalhador, Manuel António Cacheiro, que fazia parte do grupo quando apareceram os discos (BERNARDo 2002).

Esta última, relatada pelo Pe. Bonifácio Bernardo, antigo pároco nos Fortios, informa que o achador, identificado como José Conchinhas (em vez de Casquinha, o que poderá corresponder a dois apelidos ou a apelido e alcunha), tirando do bolso uma mão cheia de discos terá mostrado durante a "aguada" (pausa no trabalho para beber água e fumar um cigarro) a imprevisível descoberta. Tal feito levou, de imediato, dois dos trabalhadores (Joaquim Francisquinho e Manuel António Cacheiro) a correram ao local preciso e escavarem com as mãos, o que permitiu ao primeiro apanhar um botão e ao segundo mais dois botões; neste caso, o trabalhador viu-se obrigado a entregar um deles e, mais tarde, acabou por vender o outro na "ourivesaria dos Correias", na rua do Comércio, em Portalegre, por cinquenta mil réis (BERNARDo 2002: 27).

Conimbriga, 53 (2014) 31-79 
$\mathrm{Na}$ entrevista realizada a 27 de Outubro de 1980 pelo Eng. ${ }^{\circ}$ João Carlos Azeredo, que visitou nessa altura, juntamente com o achador, o local (propriedade sua) onde os discos foram encontrados, a versão dos factos é ligeiramente distinta. Refere-se o aparecimento inicial de oitenta e dois botões, a que se seguiram outros três, confirmando-se a ocorrência do achado no rego aberto pela charrua em conjunto com uma vasilha de barro com a forma e tamanho de meia laranja (AzEREDo 1980).

As fontes referem ainda que, posteriormente, foi informado o rendeiro e, por este, o dono da propriedade. Ainda segundo esta última fonte, os discos terão sido distribuídos pelo achador (que ficou com vinte e quatro e os vendeu depois por $30 \$ 00$ cada), pelos outros dois trabalhadores (cada um ficou no final com um disco) e pelo rendeiro, que ficou como depositário dos restantes destinados ao proprietário do terreno (que recebeu apenas onze discos) e ao Estado.

Parece ainda ter corrido a notícia de que, além dos discos, também havia alguns cordões, mas tal não foi confirmado (BERNARDO 2002: 27) nem se conhece qualquer outra referência sobre o assunto.

A singularidade e circunstâncias da ocorrência reforçam a ideia de que se trata de um conjunto intencionalmente depositado. Trata-se, por conseguinte, de um depósito constituído, segundo a informação disponível, por oitenta e oito discos (ReIs 1938; Heleno 1939) (Anexo 1), ou oitenta e cinco ${ }^{4}$, todos iguais, ocultados num recipiente cerâmico, que teria a forma de uma laranja (ou meia laranja) (REIS 1938; Heleno APMH-2-2-9-1-6-2/4; AzEREDO 1980). Considerando que a profundidade a que poderia chegar a charrua seria de cerca de $30 \mathrm{~cm}$, será essa a profundidade máxima aproximada para a deposição.

\section{As colecções}

Como vimos, e à semelhança de muitos outros casos, logo depois de terem sido encontrados, os discos dispersaram-se, tendo sido ven-

${ }^{4}$ Tendo sido impossível esclarecer o assunto, o que não põe em causa o significado deste depósito com várias dezenas de peças, tomamos como referência o número de que seriam oitenta e oito discos atendendo a que é a informação das fontes registadas na altura do achado. Não será de excluir a hipótese de que a discrepância entre as fontes, com a diferença de três discos, possa corresponder aos que terão sido fundidos na altura, com base na informação de Heleno (APMH-2-2-9-1-6-4/4).

Conimbriga, 53 (2014) 31-79 
didos na sua esmagadora maioria. Por isso, um dos nossos primeiros objectivos foi o de desenvolver esforços no sentido de se aceder ao maior número de peças (sabendo-se, porém, que a recuperação integral de origem nunca seria possível) hoje pertencentes a, pelo menos, três colecções distintas (Gráfico 1).

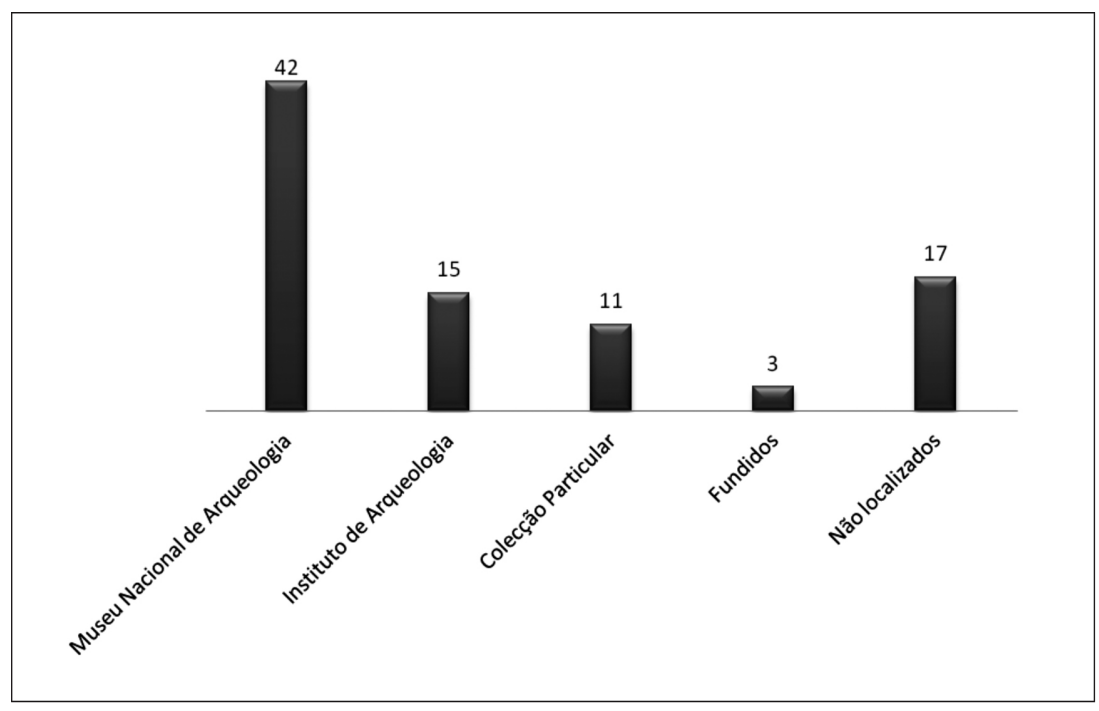

GRÁFICO 1

Do total de oitenta e oito discos foi possível localizar sessenta e oito, ignorando-se o paradeiro de dezassete, tendo em conta a notícia de que três dos discos terão sido fundidos logo na altura (Heleno, 1939) (Anexo 2). Não sabemos qual a origem desta informação registada por Manuel Heleno, que nenhuma outra fonte refere.

Uma das colecções é composta pelos quinze discos do acervo do Instituto de Arqueologia da Universidade de Coimbra. Foram adquiridos a 3 de Julho de 1969 a um ourives na casa Almeida, Basto \& Piombino (Lisboa) por Gustavo Marques, que, posteriormente, a 4 de Maio de 1974, os ofereceu àquele Instituto ${ }^{5}$.

${ }^{5}$ Informação do "Arquivo Gustavo Marques", pertencente ao Museu Nacional de Arqueologia (Lisboa) e completada com o registo documental do Instituto de Arqueologia (Coimbra).

Conimbriga, 53 (2014) 31-79 
Uma outra, a do Museu Nacional de Arqueologia ${ }^{6}$, reúne quarenta e duas peças obtidas por compra ou doação: trinta e nove $\left(n^{\circ} \mathrm{s} 228\right.$ 266) foram compradas pelo Estado ao longo dos anos de 1939 (HeLENO, 1939), 1940, 1941, 1942 e 19447; PARREIRA 1980); duas outras ( $\mathrm{n}^{\circ} \mathrm{s}$ 988-989), oriundas da colecção privada "Barros e Sá”, ingressaram no museu em 1987 (Fernandes e CorReia 1994: 505); em 2010 foi incorporado mais um disco (Au 1214), por doação da Santa Casa da Misericórdia de Lisboa, proveniente da antiga colecção particular de Delmira Maçãs.

A terceira colecção é privada, conservando onze discos pertencentes à família (não dez, como afirma Heleno em 1939) do proprietário do terreno onde apareceram as peças, Dr. Ernesto Mexia de Almeida ${ }^{8}$, tendo merecido já breve apontamento (FERREIRA 1974).

Ideal e independentemente das vicissitudes por que passaram os discos, todos os que foram localizados mereceriam ser reunidos num único espaço numa aproximação à sua condição original de conjunto mas, nessa impossibilidade, deixamos o nosso contributo expresso através de imagem onde reunimos os discos que observámos pertencentes às três colecções (FIG. 2).

É de consenso geral que estas peças, e outras congéneres, teriam sido inicialmente utilizadas como elementos decorativos aplicados sobre vestuário. As características morfo-tipológicas e tecnológicas dos discos permitem atribuir o conjunto aos inícios da Idade do Ferro (sécs. VIII-VII a.C.), cronologia que, desde a primeira notícia, foi bem percebida, como se depreende do próprio título, "Um tesouro de

${ }^{6}$ Em 2010, pudemos analisar e fotografar (fotos de B. Armbruster) os discos do Museu Nacional de Arqueologia por autorização do (então) seu Director, Dr. Luís Raposo, a quem agradecemos. De igual forma, agradece-se ao actual Director, Dr. António Carvalho, a autorização para publicar a documentação consultada no “Arquivo Dr. Manuel Heleno" (Anexos 1 a 4). Nesta pesquisa contámos com a preciosa colaboração da Dr. a Ana Melo, responsável pelo Arquivo, a quem testemunhamos o nosso reconhecimento.

${ }^{7}$ Agradecemos à Sr. ${ }^{a}$ D. Luísa Guerreiro, técnica do Museu Nacional de Arqueologia, o auxílio complementar na compilação das informações relativas às peças deste museu.

${ }^{8}$ Estamos muitíssimo gratos ao Sr. Eng. ${ }^{\circ}$ João Carlos Azeredo Leme, actual proprietário dos discos, por todas as informações disponibilizadas, incluindo o manuscrito da entrevista por si realizada ao achador das peças, bem como por nos ter recebido em Lisboa, em sua casa, onde pudemos observar e fotografar os onze discos.

Conimbriga, 53 (2014) 31-79 
há 3.000 anos...” e conteúdo, “... devem pertencer à primeira Idade do Ferro da península..." (ReIs 1938), e que tem merecido, aliás, sintonia por parte dos investigadores (v.g. PARREIRA 1980; Correia et al. 2013).

Apenas num caso, e sem fundamentação explícita, é proposta uma cronologia do Calcolítico (FerreIra 1974: 82). Para tal, o autor socorre-se apenas da semelhança com os discos de Cabeceiras de Basto (Braga) - na realidade com diferenças importantes - e defende que se trata de réplicas em ouro dos botões de osso e de marfim da "cultura do vaso campaniforme".

\section{4. À procura de um lugar}

Identificadas as condições de deposição e reagrupados os discos possíveis, era necessário encontrar um lugar para o depósito e seu contexto.

Partindo da pesquisa bibliográfica e documental, a que se juntaram informações orais e análise cartográfica, foi possível localizar a área do achado, com o reconhecimento directo do local, que nos mereceu quatro visitas, uma delas acompanhados pelo Eng. ${ }^{\circ}$ Azeredo, que havia visitado o sítio em 1980 com o achador dos discos, conforme referimos atrás. E tudo nos conduz para um lugar concreto na "Serra do Pojinho", designação actual da "Serra de Cochines", expressão registada nas Memórias Paroquiais de 1758 (Bernardo 2002: 28), onde deverá ter existido um sítio de habitat, independentemente da sua natureza e cronologia específicas.

$\mathrm{Na}$ altura precisa da descoberta dos discos (e do recipiente cerâmico que os acolhia) não se registou o aparecimento de outros elementos arqueológicos. No entanto, algumas informações bibliográficas apontaram, desde início, para a existência de um castro no local (ou próximo do local) do achado (ReIs 1938; Bernardo 2002: 24).

Aliás, o próprio registo toponímico da planície setentrional adjacente àquela serra reporta-se a uma mesma natureza habitacional da zona, pois, de forma sugestiva, a ribeira que aí corre é designada por "Ribeira da Rua de Crasto", evocando, simultaneamente, a existência de antigo caminho que levava de Fortios à vila do Crato.

Também a correspondência epistolar enviada por António Eusébio Benito Maçãs (1883-1975) a Manuel Heleno, à época director do actual 
Museu Nacional de Arqueologia, é igualmente elucidativa. Em carta datada de 1940, afirma que no sítio "[...] se encontram os restos de um castro e onde por diversas vezes teem aparecido outros objectos antigos.” (MAÇÃs, 1940) (Anexo 3). Aliás, António Maçãs chega mesmo a afirmar numa outra missiva (não datada mas cujo envelope tem carimbo do mesmo ano) que "ali verifiquei que foi sítio muito habitado, por ver nelle muitos fragmentos de barro como $V$. Ex. ${ }^{a}$ pode ver, pelo que the enviei hoje para o Museu. Vão dois pacotes com fragmentos de barro de dois sitios, como indico nos papéis dos embrulhos." (MAÇãs, 1940) (Anexo 4).

Infelizmente, os nossos esforços de identificação destes fragmentos cerâmicos, ao que parece provenientes de dois sítios (não sabemos se de estações distintas ou se de dois locais diferentes da serra) e que terão dado entrada em 1940 no Museu Nacional de Arqueologia não tiveram êxito.

Mas, no âmbito deste estudo, as prospecções realizadas proporcionaram também o achado de alguns fragmentos cerâmicos. É certo que são pequenos fragmentos lisos (dois bordos convexos e alguns fragmentos de bojos) bastante rolados, de fabrico manual, o que, não confirmando de modo algum contemporaneidade com a cronologia proposta para os discos, também não a desdiz. Todavia, denunciam ocupação antiga do lugar, como é igualmente voz corrente entre os populares da região e tal como António Maçãs preconizava, ao lamentar também não haver dinheiro para se realizar escavações (Anexo 4). A sua recolha fez-se em distintos pontos da vertente setentrional da serra, aquela que prospectámos.

As informações que reunimos comportaram ainda preciosas pistas colhidas junto de habitantes locais e, sobretudo, as que nos foram prestadas pelo Eng. ${ }^{\circ}$ Azeredo, quer no local, quer em sua casa, quer as do documento manuscrito que nos disponibilizou (AzEREDo 1980) . $^{9}$.

Em síntese, todas são concordantes no sentido de localizar o sítio de achado em área pertencente à "Herdade da Fonte Alta". Parte desta herdade espraia-se na planície, incluindo a Rua de Crasto e a Fonte Alta, mas abrange igualmente ampla área daquela serra que, nesta propriedade, toma o nome de "Serra do Pojinho", conforme já aludimos,

\footnotetext{
${ }^{9}$ Informação directa no campo, em Agosto de 2014, do Eng. ${ }^{\circ}$ Azeredo Leme e entrevista realizada a 13 de Janeiro de 2015 em sua casa.
}

Conimbriga, 53 (2014) 31-79 
ou ainda "Serra da Fonte Alta". Em outras partes, a serra é conhecida por designações distintas em função das herdades pertencentes a diferentes proprietários.

Esta serra, que se desenvolve ao longo de aproximadamente $2,5 \mathrm{~km}$ e atinge a cota máxima de $452 \mathrm{~m}$, destaca-se na peneplanície existente a sul e a poente da aldeia de Fortios (FIG. 3). Toda a área é bem irrigada. A norte corre a Ribeira da Rua de Crasto e a oriente o Ribeiro de Almojanda, afluente da Ribeira de Seda. Porém, são os altos relevos dos cerca de $40 \mathrm{~km}$ de extensão da Serra de S. Mamede (1027 m), a mais elevada a sul do Tejo (Ribeiro 1945: 60) que, a nordeste e a oriente, recortam os horizontes e são a referência paisagística nesta sub-região do Alto Alentejo interior. Na sua vertente granítica até Fortios, onde se destacam as elevações de S. Domingos $(528 \mathrm{~m})$ e de Mata Amores (586 m), configura o chamado "degrau de Fortios", patamar com cerca de $7 \mathrm{~km}$ de largura e cotas entre os $300 \mathrm{e}$ os 400 m (Almeida e FeIo 1980: 32; Gonçalves 1973).

Mas da "Serra do Pojinho" a vista alcança distantes horizontes (FIG. 4), nomeadamente para norte e poente, compreendendo-se o seu interesse estratégico a nível regional. O fraguedo granítico torna-a ainda mais acidentada e, não obstante o denso coberto vegetal arbustivo e arbóreo que hoje lhe confere um aspecto bem diferente do de há oitenta anos, foi possível identificar o local aproximado do achado dos discos. Trata-se de pequena plataforma definida pelas curvas de nível de 400$405 \mathrm{~m}$ situada a noroeste do vértice geodésico "Crucieira", onde pontuam alguns afloramentos graníticos e resiste antiga azinheira (FIG. 5).

A proposta de localização que apresentamos resulta da relocalização da área circundante no terreno, contando, para o efeito, com o auxílio de GPS. Obtida a coordenada, foi importada para um Sistema de Informação Geográfica (SIG), o open source QGIS, versão 2.0.1. Dufour. Com recurso ao programa, construímos vários suportes cartográficos, a diferentes escalas, visando inscrever a área do achado no espaço físico e administrativo. Em função disso, usámos a Carta Militar de Portugal - Série M888 (1: 25 000) folhas 347 (Fortios) e 359 (Portalegre), um Modelo Digital de Terreno (MDT) e de Elevação (MDE) e a rede hidrográfica. Por fim, realizámos um buffer, com um raio de 150 metros, sobre a coordenada obtida (FIg. 6 e 7).

Em termos administrativos, o sítio enquadra-se na freguesia de Crato e Mártires, concelho do Crato. A proximidade relativamente à aldeia de Fortios, pertencente já ao vizinho concelho de Portalegre, aca- 
bou por dar, desde o início, o nome ao achado. Uma vez feita aqui esta correcção, optámos por não alterar a designação do nome do depósito, o que provocaria inevitáveis perturbações de identificação entre a comunidade científica. Mas, na verdade, numa das referências iniciais, a informação dada não podia ser mais correcta. António Maçãs, numa das missivas enviada a Manuel Heleno, em 1940, diz: "Fui ver o local onde apareceram os botões de ouro, no termo do Crato perto da freguesia de Fortios, Portalegre..." (MAÇÃs, 1940).

\section{Os discos}

A observação directa e a análise macroscópica (em alguns exemplares recorreu-se a lupa binocular) dos 68 discos localizados permite-nos sublinhar como é notável a sua similitude. De facto, os discos são todos iguais uns aos outros. Esta constatação dispensou (e nem era esse o objectivo) o estudo individualizado e pormenorizado de cada um, que se circunscreveu exclusivamente aos da colecção de Coimbra (QUADRO 1 e Fig. 8).

QuAdro 1

\begin{tabular}{|l|l|l|l|l|}
\hline $\begin{array}{c}\text { N. }{ }^{\mathbf{0}} \text { de } \\
\text { inventário }\end{array}$ & $\begin{array}{c}\text { Diâmetro } \\
(\mathbf{c m})\end{array}$ & $\begin{array}{c}\text { Peso } \\
(\mathbf{g})\end{array}$ & \multicolumn{1}{|c|}{ Presilhas } & \multicolumn{1}{c|}{$\begin{array}{c}\text { Estado de } \\
\text { conservação }\end{array}$} \\
\hline Iarq. 1 & 2 & 1,3 & lisa/mediana & \\
\hline Iarq. 2 & 2 & 1,4 & lisa/curta & \\
\hline Iarq. 3 & 1,9 & 1,1 & lisa/mediana & \\
\hline Iarq. 4 & 2 & 1,1 & lisa/mediana & \\
\hline Iarq. 5 & 1,9 & 1,1 & lisa/curta & deformado \\
\hline Iarq. 6 & 1,9 & 1,1 & lisa/curta & \\
\hline Iarq. 7 & 2 & 1 & lisa/mediana & deformado \\
\hline Iarq. 8 & 2 & 1,1 & lisa/curta & muito deformado \\
\hline Iarq. 9 & 2 & 1,1 & lisa/mediana & deformado \\
\hline Iarq. 10 & 2 & 1,2 & lisa/longa & \\
\hline Iarq. 11 & 1,9 & 1,1 & lisa/longa & \\
\hline Iarq. 12 & 1,9 & 1,1 & lisa/mediana & deformado \\
\hline Iarq. 13 & 2 & 1,4 & lisa/torcida/mediana & com fissuras \\
\hline Iarq. 14 & 2 & 1,3 & lisa/torcida/longa & \\
\hline Iarq. 15 & 2 & 1,4 & lisa/torcida/longa & com fissuras \\
\hline
\end{tabular}

Conimbriga, 53 (2014) 31-79 
As diferenças de pormenor, muito mínimas, resultam evidentemente do fabrico manual das peças e verificam-se mais ao nível do estado de conservação (FIG. 9 a, b, c), se bem que todos se encontrem completos, mas nuns casos amolgados (por ex. Iarq. 5, 8 e 12 ) ou com pequenas fissuras de distinta intensidade (por ex. Iarq. 13 e 15). Apenas os elementos de fixação, que comentaremos adiante com maior pormenor, revelam algumas diferenças.

Trata-se de peças de ouro laminado discoidais, portanto, circulares e aplanadas, com decoração (FIG. 10). Os diâmetros são praticamente idênticos, entre 19 e $20 \mathrm{~mm}$, sendo a "altura" do relevo cinzelado das peças de $0,1 \mathrm{~cm}$; de facto, pela forma e tipo de decoração, não é possível determinar com rigor a espessura propriamente dita da lâmina, que de 0,09 a $1 \mathrm{~mm}$.

O anverso apresenta decoração obtida por puncionamento de matriz simples ou dupla e obedece a um modelo concêntrico que parte de meia calote rodeada por seis estrias em relevo regularmente distanciadas entre si. O bordo é rematado com fio de arame torcido, de secção quadrangular, mas com distintos graus de torsão e extremidades justapostas; a sua espessura é de 0,6 a $0,7 \mathrm{~mm}$ (FIG. 11). O reverso possui ao centro uma delgada haste de ouro martelado funcionando como elemento de fixação sobre um suporte. Esta tira é ligeiramente arqueada para permitir a passagem de um fio.

Se o sistema de ligação é igual em todos os casos, já o não são as presilhas, também de secção quadrangular, que apresentam variantes (QUADRO 1 e Fig. 12 a, b e c). Umas são integralmente lisas, outras apresentam-se com uma metade lisa e plana e a outra parte torcida. As diferenças registam-se ainda na dimensão das presilhas. Umas são curtas, outras um pouco maiores, mas outras são longas, atingindo, neste caso, o limite dos bordos. Esta diversidade foi igualmente observada nos discos das outras duas colecções. As extremidades são achatadas em forma de leque, o que facilitou a ligação à lâmina de base.

Pelas condições de estudo, bastante diversas entre as três colecções, não foi possível determinar de igual forma o peso dos sessenta e oito discos observados. O Quadro 1 reporta-se apenas aos pesos dos quinze discos do Instituto de Arqueologia.

Mas logo na primeira notícia, Pedro Batalha Reis (1938) refere o peso das peças que, de acordo com os valores determinados, variava de 
$1,15 \mathrm{~g}$ a $1,30 \mathrm{~g}^{10}$. Nos catálogos relativos aos discos do Museu Nacional de Arqueologia indica-se apenas um peso médio de 1,4g (PARREIRA 1980: 15; Fernandes e CoRreia 1994: 505). Para os discos da colecção particular de Lisboa não dispomos de informação, pois não os pesamos por se encontrarem interligados por um fio (FIG. 13). Quanto às quinze peças conservadas em Coimbra, os valores são algo distintos resultantes, necessariamente, da diferente sensibilidade das balanças utilizadas, perfazendo um total de $17,8 \mathrm{~g}$. Por aproximação e tendo como referência os oitenta e oito discos originalmente encontrados, poderíamos fazer um cálculo aproximado para o peso total do conjunto que, independentemente do valor, seria sempre muito modesto.

De entre os discos conservados em Coimbra, foi possível estudar quatro exemplares ( $\mathrm{n}^{\circ} \mathrm{s} 9,13,14$ e 15) no Laboratorio de Microscopía Eletrónica y Microanálisis (CSIC, Madrid), recorrendo à Microscopia Electrónica de Varrimento (MEB) e ao estudo microanalítico por Energia Dispersiva de Raios X (EDRX). Os resultados obtidos e respectiva discussão, que nos permitiram fazer o seu estudo topográfico e estrutural, bem como determinar a composição elementar das ligas e a identificação do tipo de solda utilizado, serão oportunamente publicados na íntegra, conforme já referimos (Perea et al. no prelo) ${ }^{11}$.

De momento, podemos dizer que o material utilizado no fabrico dos discos é uma liga à base de ouro com conteúdos de prata abaixo dos $10 \%$ e de cobre no limite da deteç̧ão do sistema, em torno de $1 \%$. Confirmou-se igualmente a utilização de uma liga distinta para soldar os fios e presilhas à lâmina.

Algumas peças similares às de Fortios, a que dedicaremos o próximo ponto, foram também alvo de análises cujos resultados, quando discutidos globalmente, deverão ter em conta o recurso a diferentes protocolos analíticos utilizados. Entre essas peças contam-se os exemplares de El Carambolo (Sevilha), que revelaram a utilização de solda (PereA e Hunt-Ortíz 2009) e os discos do Castro dos Ratinhos (Moura), do Outeiro da Cabeça (Torres Vedras) e um exemplar de Fortios (distinto

\footnotetext{
${ }^{10}$ Não se estranha o rigor desta informação tendo em conta que o autor, ilustre numismata e antigo aluno de Leite de Vasconcelos, era também perito qualificado da casa Almeida, Basto \& Piombino \& C. a., onde os discos estiveram à venda (Brazão 1968).

${ }^{11}$ Um dos discos pertencentes ao Museu Nacional de Arqueologia tinha sido já analisado (Pingel 1992: 298, Taf. 103).
}

Conimbriga, 53 (2014) 31-79 
dos agora analisados), onde "no traces of solder were identified" (SoARES et al. 2010: 509).

Em síntese, os discos atribuídos a Fortios revelam um único processo de fabrico, homogéneo, em série, numeroso, com o assinalável número de quase nove dezenas de peças idênticas nas quais se usou uma única matriz decorativa. Pequenas diferenças detectadas, como sucede com a forma das presilhas, pode denunciar trabalho de distintas mãos, porventura as de um mestre e de um aprendiz em trabalho desenvolvido conjuntamente. A todos estes aspectos, acrescem as informações arqueométricas, que revelaram a utilização de uma mesma liga de base para o fabrico das peças, configurando, tudo isto, a existência de uma oficina.

\section{Discussão}

Discos, botões e outros tipos de aplicações áureas correspondem a uma categoria de artefactos com longa tradição que remonta ao Calcolítico e Bronze Antigo.

Na Península Ibérica, é no Noroeste que encontramos os primeiros testemunhos representados pelos pares de discos de Cabeceiras de Basto (Braga) (a que também seria possível associar uma lúnula) e de Oviedo, amplamente conhecidos, revelando evidentes afinidades com discos congéneres irlandeses, de matriz atlântica (ARMBRUSTER 1993: 56-57; TAYLOR 1980).

Ao longo dos II e I milénios a.C. continuaram a produzir-se peças desta natureza, expressando o território hoje português um número muito assinalável de ocorrências, recentemente sistematizado mas que carece de estudo global que atenda a múltiplas vertentes (VILAÇA e ARMBRUSTER 2012: 157-158). Note-se, todavia, que esses registos correspondem a realidades formais e dimensionais muito distintas, com consequente uso, simbologia e interpretação cultural igualmente diversos, tal como o é o número de peças por achado (Gráfico 2), aspectos que se reflectem, justamente, nas próprias denominações utilizadas: botões, discos, cones, apliques, brácteas, tutuli, etc.

Conimbriga, 53 (2014) 31-79 


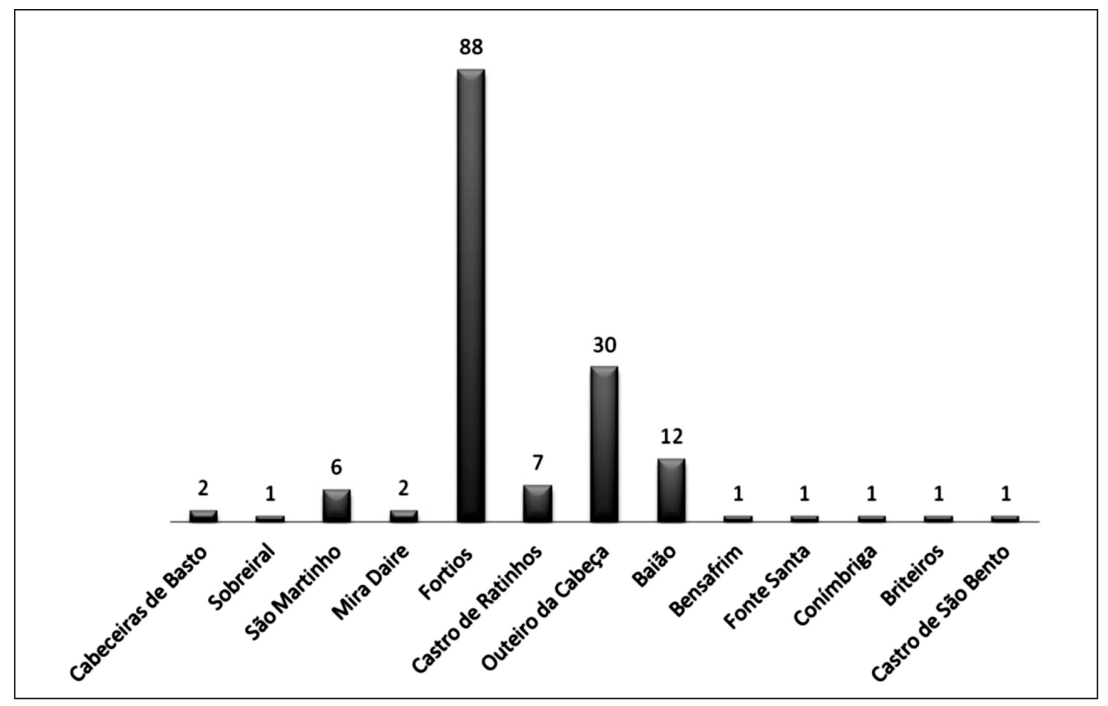

GRÁFICO 2

As peças de Fortios, pela forma (circular), platitude e limitada altura do relevo da lâmina, devem ser designados como discos. Possuem ainda, no reverso, pequena presilha que determina a sua funcionalidade prática. É opinião generalizada de que este tipo de peças seria aplicado sobre tecidos, vestuário, ou, eventualmente, couro. Esta hipótese será, talvez, mais remota atendendo, sobretudo, à delicadeza e fragilidade das peças.

Este sistema de fixação de discos através de presilhas não é muito anterior aos inícios da Idade do Ferro, conhecendo-se o seu uso em botões de bronze do Bronze Final, quer na Península Ibérica, quer além Pirenéus. Na ourivesaria parece ter sido adoptada só naquela altura, uma vez que nos discos, botões e apliques atribuídos à Idade do Bronze o modo de fixação era feito, sistematicamente, através de orifícios. Por exemplo, as peças de Cabeceiras de Basto (Braga), São Martinho (Alcácer do Sal) (ARMbruster e PARreira 1993: 56-57; 166-169; Correia et al. 2013: 88) ou Castañuelo (PEREA et al. 2010: 38-40) são disso bons exemplos.

O criação deste novo sistema de fixação com presilha traduz maior perícia funcional e tecnológica, tendo sido a solução não só para os discos de Fortios, como para outras aplicações contemporâneas distri- 
buídas particularmente no Sudoeste peninsular (FIG. 15): Outeiro da Cabeça (Torres Vedras) (Heleno 1935: 254-257; Soares et al. 2010), Castro dos Ratinhos (Moura) (Berrocal-Rangel e Silva 2010; SoAReS et al. 2010) e El Carambolo (Sevilha) (Perea e Hunt-Ortiz 2009). Embora se desconheça em rigor a origem de proveniência, deve ainda ser referido o Norte de Portugal a propósito do "tesouro de Baião", de cronologia um pouco mais tardia (sécs. VII-VI a.C.) (SiLva 1986: 244 e Est. CXIX).

Se bem que partilhem a mesma solução quanto ao sistema de fixação, as peças destes depósitos apresentam forma e dimensão variável, tal como é distinto o seu número (FIG. 14 e GráfICO 3) e como também o são os respectivos contextos.

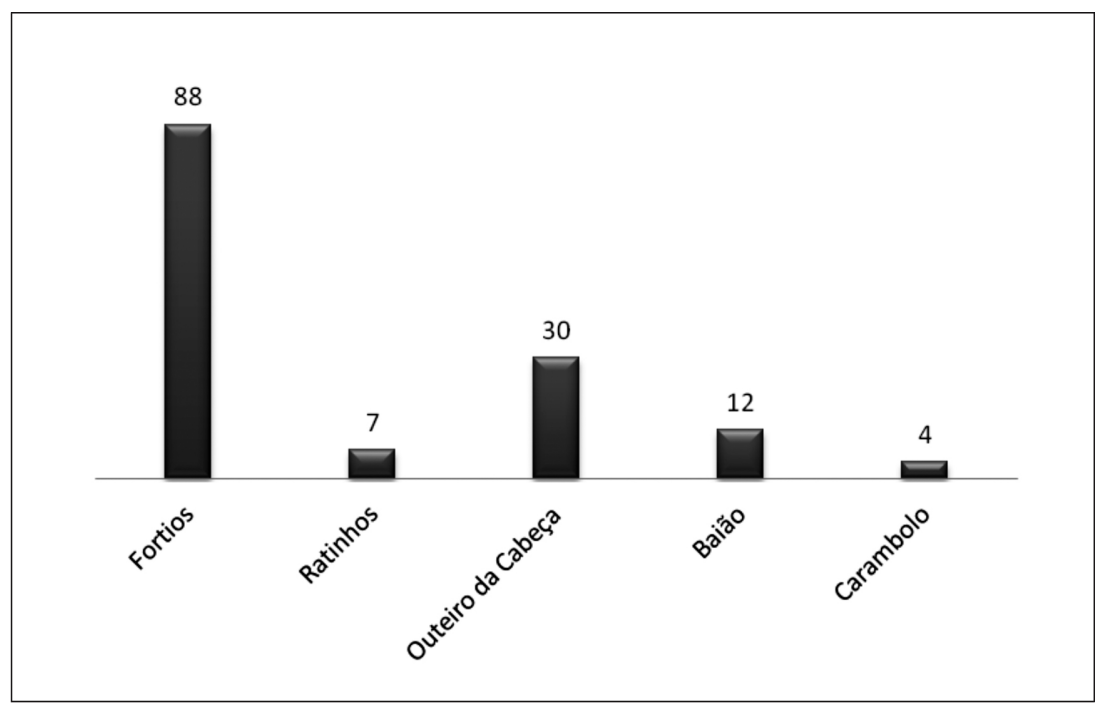

GrÁFICO 3

Em termos formais é possível estabelecer dois grupos distintos, em que se evidencia muito bem a diferença entre as formas planas dos de Fortios, Outeiro da Cabeça (FIg. 16) e Castro dos Ratinhos (FIg. 17) e as formas arredondadas onde se integram as de São Martinho e as de El Carambolo (Fig. 18) e as de Baião (Fig. 19).

Com excepção destas, aquelas fabricaram-se com a ajuda de um punção decorativo com vários círculos em relevo concêntricos, eventualmente em bronze, como os que encontramos nos depósitos france- 
ses de Génelard (Côte-d'Or) e de Larnaud (Jura) (ARMBruster 2008a).

Também só as peças de Fortios, Outeiro da Cabeça e Castro dos Ratinhos foram decoradas com a aplicação de um fio torcido sobre si mesmo que delimita o rebordo dos discos. Nos casos que observámos, verificámos uma certa irregularidade na forma e intensidade de torcer o fio, como seria de esperar numa produção manual. Neste aspecto, distanciam-se os 12 exemplares de Baião que, além da forma convexa, possuem pequena aba plana cujo rebordo está decorado com uma série de incisões oblíquas (FIG. 19), como que mimetizando conceptualmente o efeito visual do fio torcido decorativo daqueles outros.

Como referimos, o sistema de aplicação das presilhas nestes diversos conjuntos é idêntico, mas verificam-se situações distintas quanto à forma, dimensão e modo de fixação, inclusive dentro do mesmo conjunto, que vale a pena comentar.

Fortios é disso exemplo. Há discos com as presilhas totalmente planas e outros com elas em parte torcidas (QUADRO 1 e Fig. 12). Tratase de um processo de fabrico normalizado mas sem qualquer motivo funcional aparente. Esta opção mista de hastes lisas e torcidas encontra-se igualmente nas peças dos conjuntos de Outeiro da Cabeça e do Castro dos Ratinhos (Berrocal-Rangel e Silva 2010: fig. 149).

Já a sua dimensão, que em certos exemplares atinge o limite do rebordo (ou o ultrapassa), como em Iarq. 15, poderia responder a alguma finalidade mais prática em função do fio ou cordão utilizados na ligação ao suporte. Por isso, também, determinados exemplares possuem as presilhas dobradas em ângulo, formando cotovelo, enquanto outros as têm direitas, acompanhando a superfície do disco. Ou, simplesmente, as presilhas ficaram demasiado compridas, num erro de cálculo, e o ourives optou por não as cortar, antes resolver o problema dessa forma expedita. Pelo contrário, esta opção de dobrar a presilha por cima e sobre o anverso, parece ter sido a solução utilizada no material de Baião (FIG. 19), o que poderá traduzir, aqui, uma resposta alternativa para um tipo de ligação conscientemente assumida.

Outras diferenças merecem ainda ser sublinhadas, neste caso as que se observam em alguns dos discos do Outeiro da Cabeça, em que o ourives, talvez por prudência, dada a fragilidade genérica deste tipo de peças, resolveu reforçar o sistema de fixação com presilhas duplas (FIG. 20). Esta variante de presilhas duplas está presente, conforme notámos, em três dos discos de Outeiro da Cabeça do Museu Nacional de Arqueologia e repete-se em alguns dos discos do mesmo conjunto 
pertencentes ao Museu Municipal Leonel Trindade (Torres Vedras), que não observámos mas que foi devidamente sublinhado por V. H. Correia (2013).

Estas e outras especificidades são também reveladoras da criatividade particular dos ourives, inclusive no seio de uma mesma oficina de trabalho.

No delicado fabrico destas peças, nomeadamente nas de Fortios, foi necessário, além do uso de um punção decorativo, a manipulação de uma pinça para aplicar e fixar o fio torcido e as presilhas.

Pouco se sabe sobre os instrumentos de trabalho de ourives na Península Ibérica, cuja raridade foi oportunamente sublinhada (ARMBRUSTER et al. 2003), o que permite admitir também o uso frequente de instrumentos em madeira, osso e chifre. De facto, são muito raros os instrumentos de bronze e mais ainda os que configuram verdadeiros "kits de trabalho", como os de Cabezo Lucero (Alicante) (Perea e ARMBruster 2011) ou o ainda inédito de Alcácer do Sal ${ }^{12}$, em ambos os casos de meados do I milénio a.C., portanto de cronologia um pouco posterior às das peças que comentamos. Sublinhe-se que, do primeiro, fazem parte justamente duas pinças de bronze com extremidades aguçadas, próprias para o trabalho com fios (PEREA e ARMBRUSTER 2011: FIG. 4c). Para finais da Idade do Bronze, merece ser ainda mencionado, até porque bem contextualizado, o punção de bronze decorativo com motivo circular da Moreirinha (Idanha-a-Nova) (VILAÇA 1995: 228, 338 e Est. 245-3; ARMBRUSTER 2008b: 64-65).

Num outro registo, importa ainda comentar a regularidade das peças de cada conjunto em termos de dimensão e de peso.

As de maior dimensão são as de Fortios, com 1,9 e 2 cm, seguidas das de Outeiro da Cabeça e de Baião, em ambos os casos com 1,6 e $1,7 \mathrm{~cm}$, Castro de Ratinhos, com 1,04 cm e $0,95 \mathrm{~cm}$, sendo os mais pequenos os de El Carambolo, com apenas $0,2 \mathrm{~cm}$ de diâmetro de média (FIG. 15). Mas estas assinaláveis diferenças são apenas a nível comparativo, uma vez que cada conjunto é pautado, pelo contrário, por impressionante homogeneidade interna, que se reflecte, evidentemente também, nos pesos das peças por depósito, onde são mínimas as oscilações. De novo, Fortios é um bom exemplo, variando o peso dos discos entre $1 \mathrm{~g} \mathrm{e} 1,4 \mathrm{~g}$ (QUADRO 1), sendo um pouco maior a diferença entre as

${ }^{12}$ Em estudo por Ana Margarida Arruda, a quem agradecemos a informação.

Conimbriga, 53 (2014) 31-79 
peças do Castro dos Ratinhos, que variam entre 0,35g e 0,43 g (BERRoCAL-RANGel; SiLva 2010: 321).

Este elevado grau de normalização das produções da época exigiria apertado controlo de matéria-prima, com rigorosa medição das suas quantidades. Por isso, o recurso a sistemas de controlo com pe$\operatorname{sos}^{13}$ e balanças seria uma necessidade prática, como vinha a acontecer desde finais da Idade do Bronze e transição para a Idade do Ferro em contextos indígenas do Ocidente peninsular (VILAÇA 2003; 2011; ARMBRUSTER 2008 b: 34-35). A este propósito, é de significativo interesse a associação do coerente conjunto de ponderais de Baleizão (Beja) a um pequeno lingote de ouro e a dois fragmentos de fio torcido (como o utilizado nos discos de Fortios) dados a conhecer por Vilaça e Lopes (2005). O depósito encontra-se em estudo, tendo sido feita uma primeira apresentação e valorização do mesmo em encontro científico ${ }^{14}$.

A cronologia atribuída ao depósito de Fortios, entre os sécs. VIIIVII a.C. decorre exclusivamente das características morfológicas, tecnológicas e estilísticas dos discos. A aplicação de fios torcidos decorativos, ou filigrana, e o uso de solda para os fixar, remete-nos para dois dos principais contributos (juntamente com a utilização do granulado) da tecnologia da ourivesaria de matriz mediterrânea na Península Ibérica de inícios a Idade do Ferro (Perea e Armbruster 2008).

Para os outros depósitos (com excepção do de Baião) a informação é mais consistente, seja pela diversidade dos materiais do Outeiro da Cabeça onde, inclusive, pedaços de carvão foram encontrados (Heleno 1935: 254-257), o que também contribui para a sua leitura como uma oficina de ourives (SOARES et al. 2010: 502), seja pela associação a espirais no caso de São Martinho (Armbruster e PARreira, 1993: 168; Correia et al., 2013: 233) ${ }^{15}$, seja pelos contextos cronológicos e culturais bem definidos do Castro dos Ratinhos (BERROCAL-RANGEL e SiLVA 2010) e de El Carambolo, cujas escavações dos últimos

${ }^{13}$ Recentemente, identificamos no Museu Nacional de Arqueologia mais um ponderal (inédito), neste caso atribuído ao castro do Zambujal (Torres Vedras).

${ }^{14}$ Vilaça, R., Perea, A., Armbruster, B., The Baleizão hoard (Beja, Portugal). Evidence of Late Bronze Age bronze and gold technology. Comunicação apresentada no colóquio de homenagem a Salvador Rovira, Archaeometallurgy: technological, economic and social perspectives in Late Prehistoric Europe (Madrid, 2009).

${ }^{15} \mathrm{Na}$ realidade, o achado dos botões e das 20 espirais ocorreu em momentos distintos (veja-se Heleno 1935: 232-233).

Conimbriga, 53 (2014) 31-79 
anos permitiram a reinterpretação do sítio como santuário (FERNÁNDEZ e RODRIGUEZ 2005).

O contexto dos sete discos da estação portuguesa é de especial importância por se conhecerem bem as suas circunstâncias de achado, na zona da acrópole do povoado indígena. Estavam agrupados junto à base de um pilar, ocultados em pequena cavidade no interior de um edifício sagrado da Fase 1b, com cronologia de finais do séc. IX a meados do séc. VIII a.C. (Berrocal-Rangel e Silva 2010: 108; 190-191; 322-324; 413).

Por conseguinte, e por comparação, é admissível recuar um pouco a cronologia antes proposta para os discos de Fortios. Também não é de descartar a hipótese de, no sítio ou nas suas proximidades, como bem alerta o conjunto de pistas que reunimos neste trabalho, existir um povoado e, porventura até, um espaço sagrado a ele associado. Mas só com prospecções arqueológicas de maior fôlego, designadamente nas áreas que não conhecemos, incorporando também contributos de prospecções geofísicas e, sobretudo, com escavações futuras, poderíamos comprová-lo.

Por outro lado, o qualificado trabalho desenvolvido no Castro dos Ratinhos permitiu ainda identificar junto aos discos um fragmento de tecido de que, todavia, não foi possível recuperar qualquer vestígio material mas de que ficou impressão na terra argilosa (BERROCAL-RANGEL e Silva 2010: 322) (Fig. 17). O uso que se preconiza para este tipo de aplicações e outras congéneres encontra, aqui, plena consistência.

Efectivamente, esta hipótese interpretativa decorre igualmente de outros contextos de natureza funerária da Idade do Bronze europeia nos quais se encontraram aplicações similares de bronze, que permitem visualizar as zonas do corpo (zona do peito, na linha de cintura, mas também abaixo desta) e do vestuário, a que se associavam, nomeadamente túnicas e capas, como revelam os exemplos de Lübz e Thürgkow (Mecklenburg, Alemanha), com tutuli de bronze (SсHмIDT 2007; RANDSBORG 2011: 78; 92-93).

E, caminhando ainda mais para oriente, encontramos na sepultura dupla de Arzhan (Mongólia), de um homem e de uma mulher, datada do séc. VII a.C., duas capas ornamentadas com pequenas panteras de ouro, ainda in situ, cuja distribuição não era aleatória antes configurava sugestiva forma curvilínea na zona dos ombros e costas (ARMBRUSTER 2011).

Embora muito distinta, até por ser caso único na actualidade e Conimbriga, 53 (2014) 31-79 
verdadeira obra-prima de ourivesaria do Bronze Inicial, deve ainda ser referida a capa de ouro decorada em relevo de Mold (Flintshire, País de Gales), evocando o uso excepcional de determinados adereços desde época remota (Needham 2012).

O contexto de Fortios é bem distinto de todas estas situações, pois constitui um depósito no sentido literal do termo, i.e., os discos foram intencionalmente ocultados em conjunto no interior de um recipiente, e, como tal, estavam "disfuncionalizados". Mas estas analogias permitem-nos colocar a hipótese de que, em algum momento da sua "biografia cultural" terão adornado o manto, a capa ou o vestuário de um personagem com prestígio sócio-político e, eventualmente, também sagrado. Teriam sido utilizados (ou destinavam-se a ser utilizados) na sua totalidade sobre um único suporte, conforme propomos numa interpretação livre expressa na FIG. $21^{16}$. Ou seriam destinados a adornar mais do que um suporte? Nunca o saberemos. Neste caso, o local onde foram ocultados poderia corresponder a centro produtor e distribuidor deste tipo de peças.

Certo é o elevado valor material e simbólico dos discos, que conferiam prestígio a quem os exibisse. O uso de vestuário específico como estratégia diferenciadora em termos de status, de género, de idade e de identidade, e especialmente como forma de afirmação de elites em cerimoniais públicos, adquiriu particular importância na Idade do Bronze e durante a Idade do Ferro. No caso de Fortios fica em aberto a possibilidade das vestes ornamentadas com os discos terem acumulado ou integrado uma vertente também ritual e sagrada, que parece subjacente, pelos respectivos contextos, aos conjuntos do Castro dos Ratinhos e de El Carambolo.

A simbologia dos discos não é, porém, inequívoca. A propósito das peças de Fortios e de Outeiro da Cabeça, foi defendido que representariam escudos em miniatura por comparação com os escudos do Bronze Final, nomeadamente os figurados nas estelas ditas "de guerreiro" ou do "Sudoeste" (HARRISON 2004: 134). Esta linha interpretativa, em boa parte assente em paralelismos formais, não nos parece plenamente convincente.

Em alternativa, admitimos que o seu valor simbólico não deve-

\footnotetext{
${ }^{16}$ Autoria (tal como as figuras 10, 14 e 15) de José Luís Madeira, técnico superior da FLUC, a quem agradecemos a colaboração.
}

Conimbriga, 53 (2014) 31-79 
rá dissociar-se do imaginário solar de longa tradição, consubstanciado justamente nos designados "discos solares" que, desde o Bronze Antigo evocam esse fenómeno à escala europeia, sobretudo atlântica e setentrional (v.g. TAYLOR 1980; ARMBRUSTER 1993; GUÉRIN e ARMBRUSTER 2015). Outros discos de cronologia mais tardia, do Bronze Final, como os do conjunto da gruta de Han-sur-Lesse (Namour, Bélgica), também decorados com motivos circulares concêntricos, tal como os de Fortios, foram interpretados da mesma forma (WARMENBOL 1999).

Todavia, será sempre difícil, numa visão hodierna e ocidental, avaliar a real importância do Sol entre as sociedades arcaicas, a forma como o apreendiam e o modo como o materializavam em termos representativos e figurativos. A subtileza visual com que o Sol se expressa consoante a hora do dia e as condições atmosféricas, produzindo distintos efeitos sensoriais, foi recentemente sublinhado em interessante ensaio de Mary Cahill onde se exploram, precisamente, as hipóteses de diversas configurações decorativas visuais que encontramos nos "discos solares" e em determinadas cerâmicas: cruzes, raios, círculos concêntricos, etc. (CAHILL 2015).

\section{Notas finais}

$\mathrm{O}$ estudo dos discos de Fortios, particularmente nas vertentes em que este texto se centrou, permitiu valorizar um achado arqueológico que o tempo e os homens tinham desfigurado. Foi possível reencontrar parte do percurso da história deste conjunto, o que possibilitou igualmente abordá-lo na sua essência, i.e. na sua condição de depósito voluntário, com um contexto e um lugar escolhidos, traduzindo uma acção deliberada de ocultação de valores inestimáveis no interior de um recipiente cerâmico.

A notável homogeneidade formal, tecnológica e estilística, a que acresce um impressionante e inigualável número de discos, expressam uma produção em série, normalizada, com gestos repetidos e coordenados, com trabalho entre mestres e aprendizes, uma oficina. Assinalável é também a delicadeza das peças, bem patente na leveza de cada uma e na mestria da aplicação, com recurso a instrumentos profissionais de ourives, do fio decorativo de filigrana e do sistema de fixação. Com este novo modo de produção dava-se primazia a uma economia de tempo e de material, cortando definitivamente com um passado pautado pelas 
pesadas e maciças jóias, como os colares, braceletes e anéis do Bronze Final (sécs. XI-IX a.C.).

Os tempos eram de mudança mas esse passado não era distante, nem no tempo, nem no espaço. Pelas características técnico-decorativas e por comparação com outros conjuntos similares cujos contextos são mais bem conhecidos, propõe-se para os discos de Fortios uma cronologia por volta do século VIII a.C. E pelas peças de ourivesaria do II milénio a.C. conhecidas nesta região do Alto Alentejo, o achado de Fortios denuncia que, ao poder das elites de finais da Idade do Bronze sucedeu um outro poder, que se demonstrava e afirmava recorrendo igualmente ao corpo como veículo de o exibir cobrindo-o agora de vestes adornadas de ouro.

Os autores dos discos de Fortios constituem uma nova "escola", indígena mas atenta e aberta às linhas tecnológicas e estilísticas de timbre mediterrâneo caracterizada pela leveza, decoração impressa e filigrana, a que se junta a solda. Constituem a geração de ourives que sucedeu à dos criadores do torques de ouro martelado com terminais em forma de disco decorados com repuxado de Alegrete (Portalegre) e ao bracelete liso, também de ouro martelado, de Urra (Portalegre), neste caso lídimo representante da ourivesaria de "tipo Sagrajas-Berzocana" (ARMBruster e PARReIRA 1993, 52-53; 112-113). A este conjunto de achados áureos poderá, ou poderia, ser ainda acrescido o bracelete de "tipo Villena-Estremoz" recentemente vendido em leilão internacional e tido como proveniente de Portalegre (CORREIA 2013).

No seu todo, o grupo é muito sugestivo e faz desta região um interessante caso de estudo para os períodos das Idades do Bronze e do Ferro, ainda por explorar. Bastaria lembrar a vizinhança da Extremadura espanhola, absolutamente estratégica naquela época. E por aqui passava, desde tempos imemoriais e de modo resiliente, uma das principais rotas ligadas à transumância que, de norte a sul e cruzando o Tejo, ligava a Beira Interior aos campos de Ourique, no Baixo Alentejo, percurso igualmente marcado no rasto deixado por diversos marcadores de prestígio adscritos à Idade do Bronze, como estelas e elementos metálicos (bronze e ouro) de vestuário e de estética (GALÁn Domingo e RuIZ-Gálvez 2001: fig. 2 e 3; VILAÇA et al. 1998: 37-39). Em falta estão, nesta área, os povoados e as necrópoles, ou antes o conhecimento que deles gostaríamos de ter. Com essas valências seria mais fácil aceder e compreender o fundo ideológico subjacente à concepção e exibição dos discos de Fortios.

Conimbriga, 53 (2014) 31-79 
O lugar do seu achado é, neste momento, o mais promissor, embora outros registos não devam ser ignorados, clamando a região por um adequado programa de prospecções dirigidas para aqueles períodos. De resto, há muito que toda a área era ocupada como bem demonstram, por exemplo, os agrupamentos megalíticos da Herdade da Crucieira ( 7 antas) e das Taliscas ( 3 antas) cada um deles com um povoado conexo (PARreira 1996, 48, 78, 118), bem próximos da "Serra do Pojinho".

\section{BIBLIOGRAFIA}

Almeida, G. e Feio, M. (1980) - A serra de S. Mamede. Finisterra. Revista Portuguesa de Geografia, Lisboa, XV (29), p. 30-52.

Armbruster, B. (1993) - A lúnula e as aplicações discoidais de Cabeceiras de Basto. In Armbruster e Parreira (dir.) (1993) - Inventário do Museu Nacional de Arqueologia, 1. Do Calcolítico à Idade do Ferro, Lisboa, Instituto Português de Museus, p. 56-59; 166-167.

Armbruster, B. (2008 a) - Outillage de métallurgiste de l'âge du Bronze: les dépôts de Larnaud (Jura) et Génelard (Saône-et-Loire). Bulletin de l'APRAB 5, p. 38-41.

Armbruster, B. (2008 b) - L'Orfèvrerie dans le monde atlantique. Des origines a l'âge du Fer. Une aproche technologique, Université de Bourgogne, Dijon (mémoire inédit).

Armbruster, B. (2011) - Gold technology of the ancient Scythians. Gold from the kurgan Arzhan 2, Tuva, Archéoscience Revue d'Archéométrie 33, p. 187-93.

Armbruster, B. e Parreira, R. (dir.) (1993) - Inventário do Museu Nacional de Arqueologia, 1. Do Calcolítico à Idade do Ferro, Lisboa, Instituto Português de Museus.

Armbruster, B.; Comendador, B.; Monteiro, I.; Perea, A.; Pernot, M. (2003) Tools and tool marks. Gold and bronze metallurgy in Western Europe during the Bronze and Early Iron ages. Archaeometallurgy in Europe. Proceedings, vol. I. Milán, p. 255-266.

Armbruster, B. e Perea, A. (2011) - Tomb 100 at Cabezo Lucero: new light on glodworking in fourth-century BC Iberia. Antiquity 85 (327), p. 158-171.

AzEREDo, J.C. (1980) - Manuscrito (inédito), Lisboa.

Bernardo, B. (2002) - Aldeia dos Fortios. Memória Histórica, Lisboa, Edições Colibri.

Berrocal-Rangel, L. e Silva, A.C. (2010) - O Castro dos Ratinhos (Barragem do Alqueva, Moura). O Arqueólogo Português, Suplemento 6, Lisboa, Museu Nacional de Arqueologia.

BrazÃo, A. (1968) - Pedro Batalha Reis. Grande luminar de Numismática nacional, Nummus, Porto, IX-1/2 (29-30), p. 3-48.

Cahill, M. (2015) - 'Here comes the Sun'... solar imagery in the Bronze Age, Archaeology Ireland 29 (1), p. 26-33.

Conimbriga, 53 (2014) 31-79 
Correia, V.H. (2013) - A ourivesaria arcaica no Ocidente peninsular. Estado da questão, problemáticas arqueológicas e perspectivas de desenvolvimento do campo de estudo. O Arqueólogo Português, série V, 3 (no prelo).

Correia, V.H.; Parreira, R.; Silva, A.C. (2013) - Ourivesaria Arcaica em Portugal, Lisboa, CTT Correios de Portugal.

Fernandes, M.A.; Correia, V.H. (1994) - Um gosto privado. Um olhar público, Catálogo, Lisboa, Museu Nacional de Arqueologia.

Fernández, A. e Rodriguez, A. (2005) - El complejo monumetal del Carambolo Alto, Camas (Sevilla). Un santuario orientalizante en la paleodesembocadura del Guadalquivir. Trabajos de Prehistoria 62 (1), p. 111-138.

Ferreira, O.V. (1974) - Notícia da descoberta de jóias auríferas no distrito de Portalegre. Estudos Italianos em Portugal 37, p. 79-82.

Gago, A.; Martinho, C.; Raposo, L. (2013) - Manuel Heleno. Fotobiografia, Lisboa, Imprensa Nacional.

Galán Domingo, E. e Ruiz-Gálvez, M. (2001) - Rutas ganaderas, transterminancia y caminos antiguos. El caso del Occidente peninsular entre el Calcolítico y la Edad del Hierro. In Gómez pantoja, J. (coord.), Los rebaños de Gerión. Pastores y trashumancia en Iberia antigua y medieval, Madrid, Collection de la Casa de Velázquez 73, p. 263-278.

Gonçalves, F. (1973) - Carta Geológica de Portugal, 1/50.000, folha 32-B, Portalegre. Notícia explicativa.

Guérin, S. e Armbruster, B. (2015) - Le disque en or des dépots de Ribécourt-Dreslincourt (Oise). Bulletin de la Sociétè Préhistorique Française 112 (1), p. 148151.

Harrison, R. (2004) - Symbols and Warriors. Images of the European Bronze Age, Bristol.

Heleno, M. (1935) - Jóias pré-romanas. Ethnos 1, Lisboa, p. 229-257.

Heleno, M. - Apontamentos [Manuscrito]. 1939. Arquivo Pessoal de Manuel Heleno, Museu Nacional de Arqueologia, Lisboa [Em linha]. Disponível em http://arquivo.patrimoniocultural.gov.pt/apinet.

López PADilla, J.A. (2006) - Marfil, oro, botones y adornos en el área oriental del país de El Argar. Marq. Arqueología y Museos 01, p. 25-48.

Maçãs, A. - [Carta] 1940 Janeiro 24, Portalegre [a] Manuel Heleno [Manuscrito]. 1940. Disponível no Arquivo Pessoal de Manuel Heleno, Museu Nacional de Arqueologia, Lisboa.

Maçãs, A. - [Carta] [a] Manuel Heleno [Manuscrito]. 1940. Disponível no Arquivo Pessoal de Manuel Heleno, Museu Nacional de Arqueologia, Lisboa.

Needham, S. (2012) - Putting capes into context: Mold at the heart of a domain. In Britnell, W. e Silvester, R. (eds.), Reflections on the Past. Essays in honour of Frances Lynch (Welshpool, Cambrian Archaeological Association, p. 210-236.

Parreira, R. (1980) - Tesouros da Arqueologia Portuguesa no Museu Nacional de Arqueologia e Etnologia, Lisboa.

Parreira, R. (1996) - O conjunto Megalítico do Crato (Alto Alentejo). Contribuição 
para o registo das antas portuguesas, 2 vols., Porto, FLUP (tese de mestrado policopiada).

Perea, A. (1991) - Orfebrería Prerronana. Arqueología del Oro, Caja de Madrid. Comunidad de Madrid.

Perea, A. e Armbruster, B. (2008) - Tradicion, cambio y ruptura generacional. La producción orfebre de la fachada atlántica durante la transición Bronce-Hierro de la Península Ibérica. In Celestino, S.; Rafel, N., Armada, X.L. (eds.), Contacto Cultural entre el Mediterráneo y el Atlántico (siglos XII-VIII ane): la precolonización a debate, CSIC, Serie Arqueológica 11, Madrid, p. 497-508.

Perea, A. e Armbruster, B. (2011) - Tomb 100 at Cabezo Lucero: new Light on goldworking in fourth-century BC Ibéria. Antiquity 85, p. 158, 171.

Perea, A. e Hunt-Ortiz, M. (2009) - New finds from an old treasure: the archaeometric study of new Gold objects from the Phoenician sanctuary of El Carambolo (Camas, Seville, Spain). ArcheoSciences 33, p. 159-163.

Perea, A.; VilaçA, R.; Armbruster, B. (no prelo) - Arqueometría y contexto artesanal de los discos áureos de Fortios (Portalegre, Alto Alentejo, Portugal), Trabajos de prehistoria.

Perea, A.; García-Vuelta, O.; Fernández Freire, C. (2010) - El Proyecto Au. Estudio arqueométrico de la producción de oro en la Península Ibérica, Madrid, CSIC, Bibliotheca Praehistorica Hispana, vol. XXVII.

Perea, A.; Montero, I.; García-Vuelta, O. (2004) - Project Au. A research strategy in gold metallurgy. Tecnología del Oro Antiguo: Europa y América. In PereA, A., Montero, I. e García-Vuelta, O. (Eds.), Actas del I Symposium Internacional sobre Tecnología del Oro Antiguo (Madrid 2002), Anejos de Archivo Español de Arqueología, Madrid, p. 139-146.

Pereira, I. (coord.) (1994) - Idade do Ferro. Catálogo, Serviços Culturais, Museu. Câmara Municipal da Figueira da Foz.

Pingel, V. (1992) - Die vorgeschichtlichen Goldfunde der Iberischen Halbinsel. Eine archäologische Untersuchung zur Auswertung der Spektralanalysen, Berlin, Walter de Gruyter \& Co. Marburg Univ., Madrider Forschungen, 17.

Randsborg, K. (2011) - Bronze Age Textiles. Men, Women and Wealth, London, Bristol Classical Press.

Reis, P.B. (1938) - Um tesouro de há 3.000 anos foi achado perto de Portalegre. Diário de Notícias, 2 de Agosto de 1938, ano 74, n. ${ }^{\circ} 26037$.

Ribeiro, O. (1945) - Portugal, o Mediterrâneo e o Atlântico. Estudo geográfico, Coimbra, Coimbra Editora.

Schмidt, J.-P. (2007) - Die älterbronzezeitlichen Gräber von Thürkow, Lkr. Güstrow. Bodendenkmalpflege in Mecklenburg-Vorpommern 55, p. 67-118.

Silva, A.C.F. (1986) - A cultura castreja no Noroeste de Portugal, Câmara Municipal de Paços de Ferreira.

Soares, A.; Valério, P., Silva, R.; Alves, L.; Araújo, M.F. (2010) - Early Iron Age gold buttons from South-Western Iberian Peninsula. Identification of a gold metallurgical workshop. Trabajos de Prehistoria 67(2), p. 501-510.

Conimbriga, 53 (2014) 31-79 
TAYlor, J. (1980) - Bronze Age goldwork of British Isles, Cambridge University Press. VILAÇA, R. (1995) - Aspectos do Povoamento da Beira Interior (Centro e Sul) nos finais da Idade do Bronze, Trabalhos de Arqueologia 9, 2 vols., Lisboa, IPPAR.

VilaÇA, R. (2003) - Acerca da existência de ponderais em contextos do Bronze Final / Ferro Inicial no território português. O Arqueólogo Português, série IV, 21, p. 245-288.

ViLAÇA, R. (2011) - Ponderais do Bronze Final-Ferro Inicial do Ocidente peninsular: novos dados e questões em aberto. In García-Bellido, M.P., Callegarin, L., JimÉnez Díez, A. (eds.), Barter, Money and Coinage in the Ancient Mediterranean (10th-1st centuries BC), Anejos de AEspA LVIII, CSIC, p. 139-167.

VILAÇA, R. (2013) - Contraluz. Da ourivesaria arcaica, suas problemáticas e perspectivas de estudo na leitura de Virgílio Hipólito Correia. O Arqueólogo Português série V 3 (no prelo).

VILAÇA, R. e LoPES, M.C. (2005) - The treasure of Baleizão, Beja (Alentejo, Portugal). Journal of Iberian Archaeology 7, Porto, p. 177-184.

Vilaça, R.; Armbruster, B. (2012) - O disco de ouro da necrópole da Fonte Velha de Bensafrim, Lagos, Algarve. In VilaçA, R. e Pinto, S. (coord.), Santos Rocha, a Arqueologia e a Sociedade do seu Tempo, Figueira da Foz, Casino Figueira, p. 153-170.

Vilaça, R.; Armbruster, B.; Perea, A. (no prelo) - S'habiller pour briller. Le dépôt de disques en or du premier âge du Fer trouvé à Fortios (Portalegre, Portugal). Colloque International L'Or de lâge du Fere n Europe celtique. Société, technologie et archéométrie, Toulouse, TRACES.

Vilaça, R., Santos, A.T., Porfírio, E., Marques, J.N. e Canas, N. (1998) - Lugares e caminhos no mundo pré-romano da Beira Interior, Cadernos de Geografia, 17, Coimbra, p. 35-42.

Warmenbol, E. (1999) - Le soleil des morts. Les ors protohistoriques de Han-sur-Lesse (Namur, Belgique). Germania 77, p. 25-37.

Conimbriga, 53 (2014) 31-79 


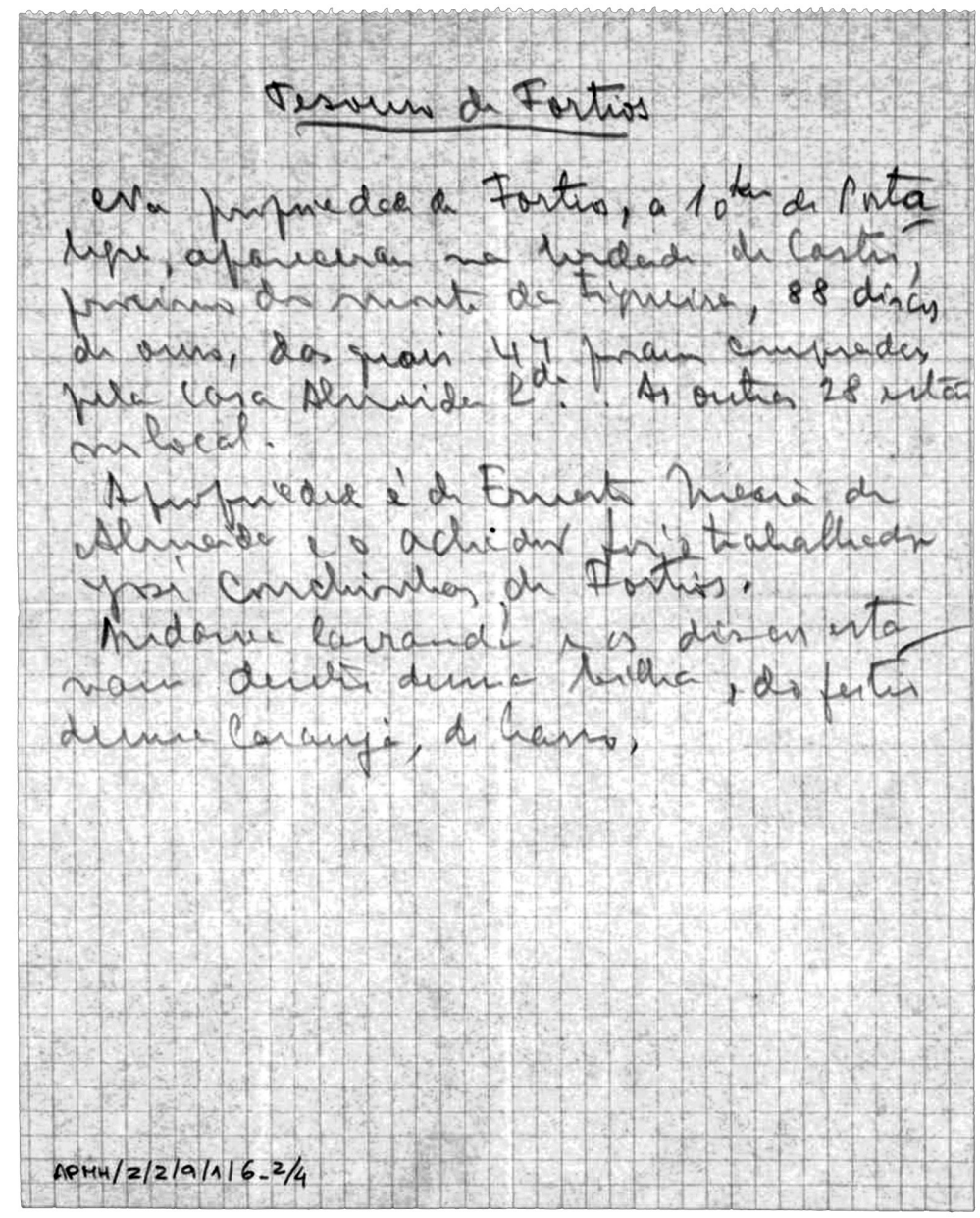

Anexo 1 
Eesoun de Fition

Puso total $-915,5$

m: di disins -88

Funchids - 3

Na vorse de

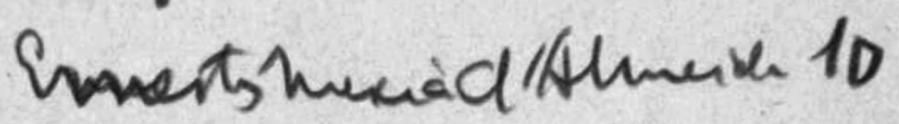

enupui 8 modie 17

dh by. 1935

APHH/2/2/9/1/6-4/4

Anexo 2 
APH $/ 5 / 1 / 415 / 1-2 / 2$

$$
M=b_{0} \sim \operatorname{Limh}
$$

Iouton crand thelems

Realmante falei as Sin or Lecike re Varconcelor, de uns hatres de antoo, afareciilos ma Argursia da

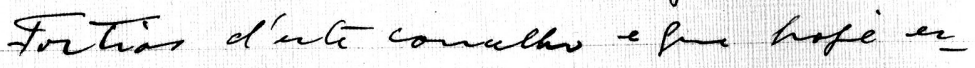
Tat a vinda, ma casa ctherida de una do ouss un foribre. Fulas foias frean encarthades, en sitio onde se encoutran as restar le tur eartas coude for diveres sefer, teen aparecido outios abjits antigos.

Anexo 3A 


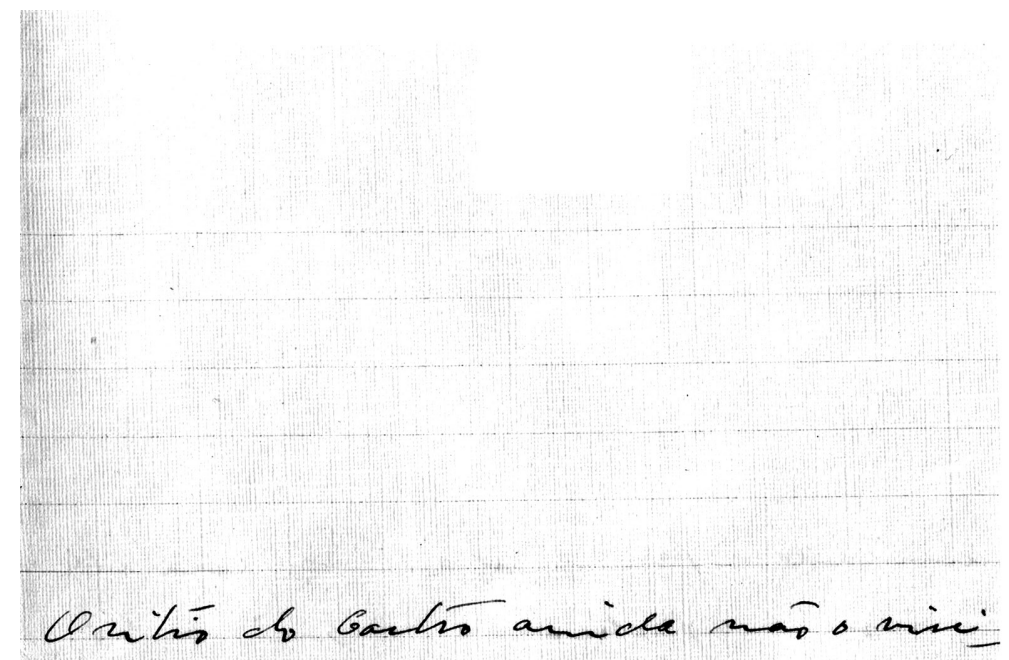

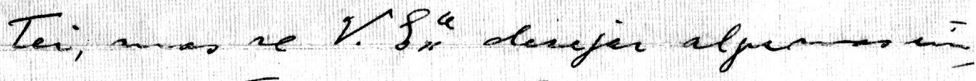
formacos man; tenha a bundade of m dyjer fre untīo o vinitatei fare esceit the foded dar relleves enformach.

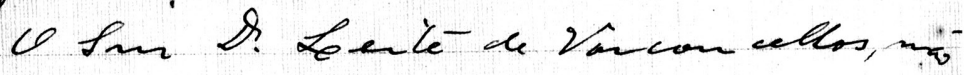
timha fere feden denculfa, porfer to

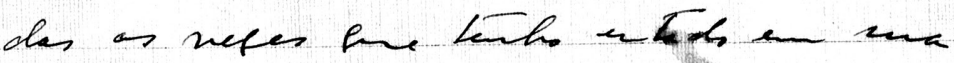
care, ne tan rechilo cotp a main

Anexo 3B 
amijade e framprosa. Pesp fara elle as mour afectuocos andiniments.

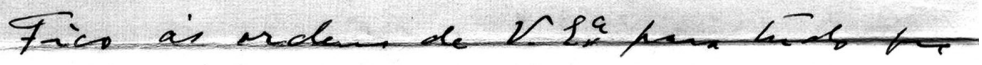

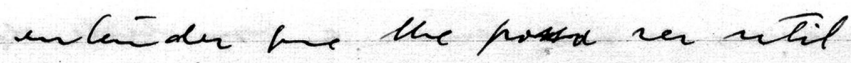

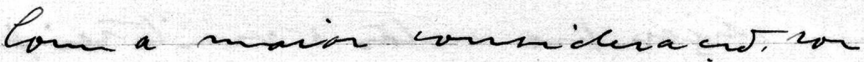

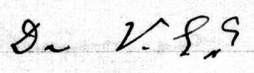

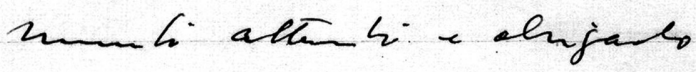

Porlathe 24 defar de 1840

Antinis buchi Itank- claces

Anexo 3C 
APM $1 / 5 / 1 / 415 / 2.2 / 2$

$H=b-2$.

Souloí cecannel Helem.

Fin ver o lral onde apancesam as butais de auldo, m. Termo do Cra

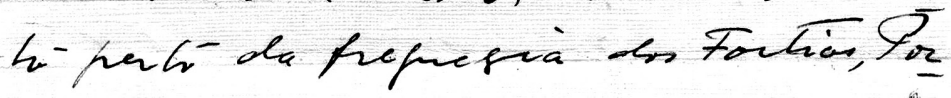
talegre $e$ ahe verifience fore for in is

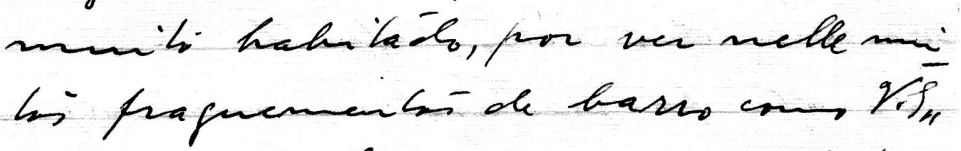
fode va, fuld fure the envier hrie fara a clewen. Vas dor fra cales on fraguentankide bases de dos: ntion, como widies mos haper dos anbsultr. Parecen. re va

Anexo 4A 


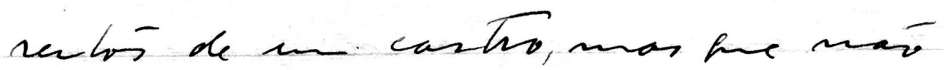

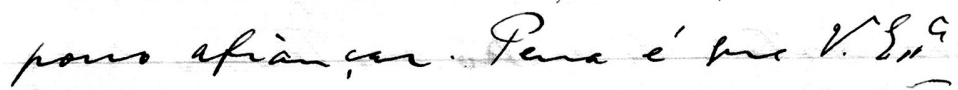
mat convija adpaini or bolos

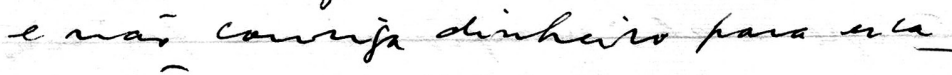
vaces des nitis sefents.

So the for hertard en maialf crin: mande.

bour a mavió conridena s 5

D. $2 . \varepsilon$

In ti ath a obnjede

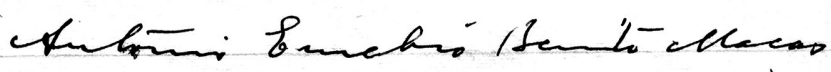

ANExo 4B 


\section{Um tesouro de há 3.000 anos foi achado perto de Pora talegre \\ Os achados arqueologicos, dando-se em re-}

gra no zampo e por pessoas que de todo desconhecem o seu interesse, raramente chegam Intelros á măo do arqueologo. mais raro ainda é ele conseguir as informaçóes que esclareçam do local exacto do achado Isto acontece nomeadamente quando sấ objectos de ouro, porque o seu achador os vende ao primelro ourives que se the depara, e desses é conheclda a sorte que the dão - a destruiçấo no cadínho! pela ignorancia aflitiva da maioria desses negociantes. De modo que se 0 arqueologo logra ter breve conhecimento de que essez objectos se encontram nalgum ourives corre apressado, compra a jola, mas năo consegue qualquer outra informaçáo que năc seja a de haver sido adquirida "a um des. conhecidors

Ora o achado de que hoje damos noticia chegou, por felicidade, ao nosso conhe.
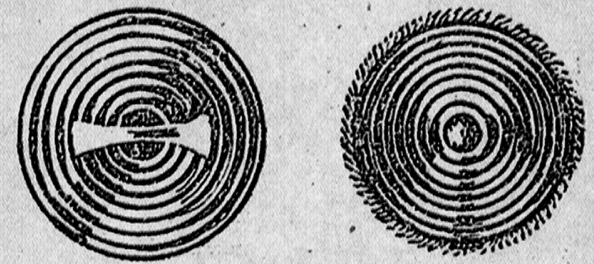

Duas das peças de ouro achadas em Fortios

cimento quasi directamente. e por Isso sem os prejuizos que apontamos.

ris o quie se passou: Quando o traba lhador José Conchinhas andava a lavrar numa propriedade denominada Rui de Cas. tro, nc lugar de Fortios, a alguns quilometros de Portalegre, notou que um dos boís batera com a pata num pucaro de barro. que tinha a forma de uma laranja, e, partindo-o dele satam as pecas que constítuem este tesouro: são oitenta e oito discos de ouro.

Estes objectos, semelhantes aos encon.

FIG. 1 - Primeira notícia relativa ao achado de Fortios publicada no Diário de Notícias de 2.8.1938. 


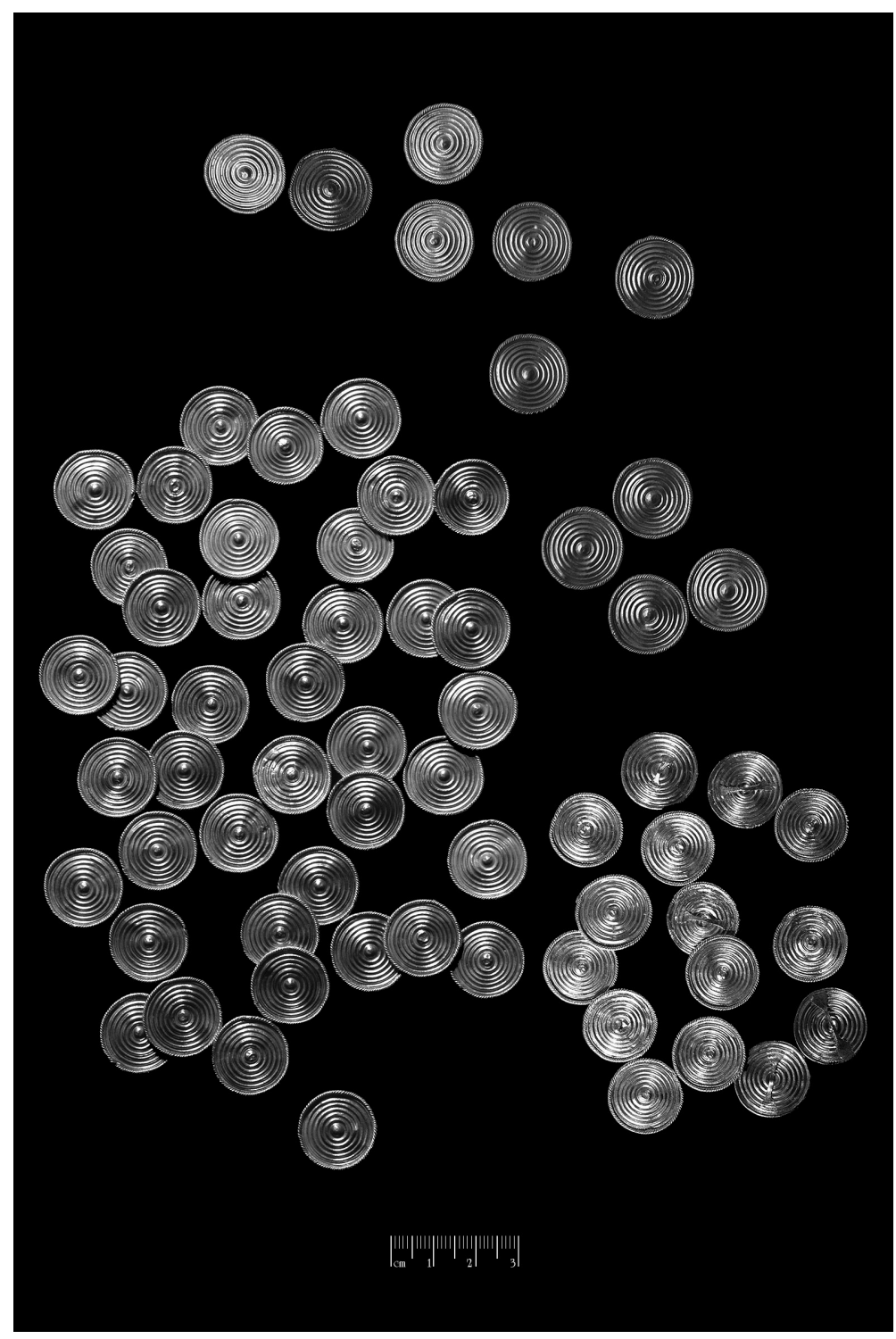

Fig. 2 - Conjunto dos 68 discos localizados. 


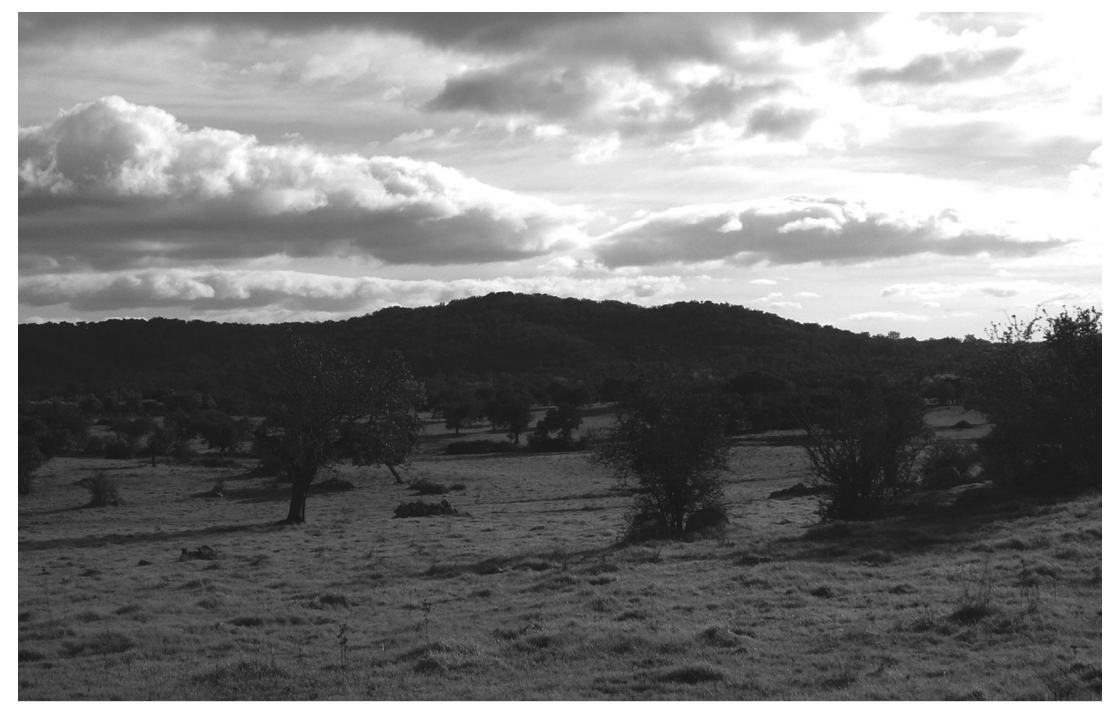

FIg. 3 - Aspecto geral da "Serra do Pojinho" na sua vertente setentrional.

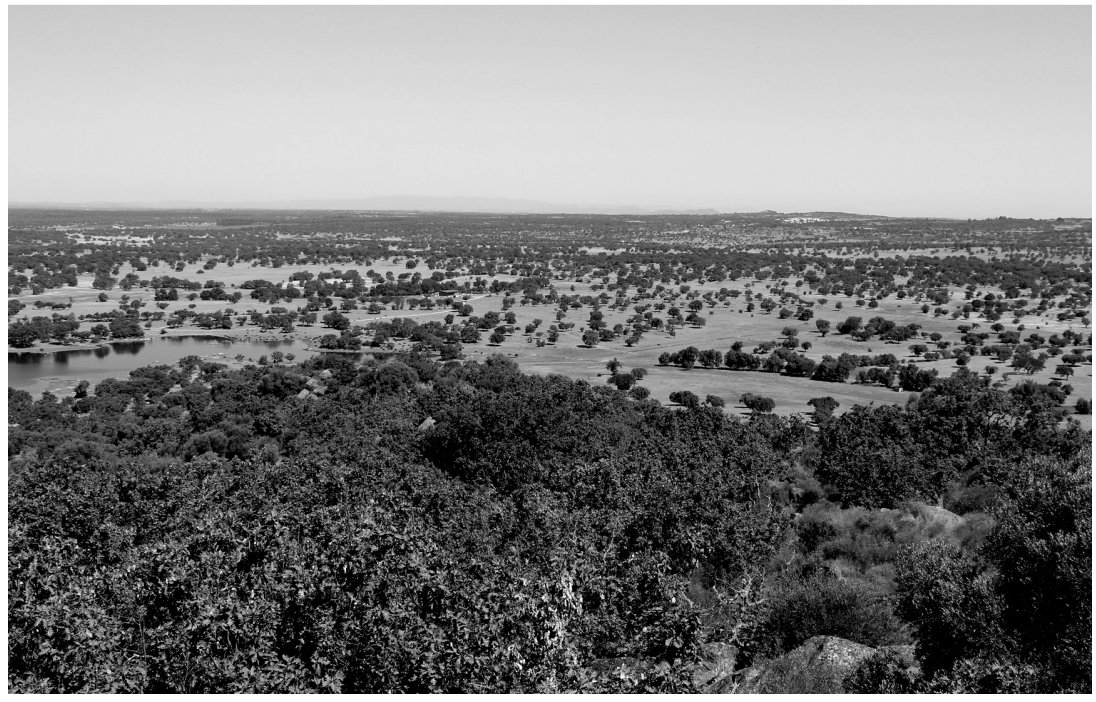

FIG. 4 - Perspectiva para norte e noroeste a partir da "Serra do Pojinho", observando-se em primeiro plano a densa vegetação que encobre o local de achado dos discos e em segundo plano o monte da Fonte Alta na planície. 


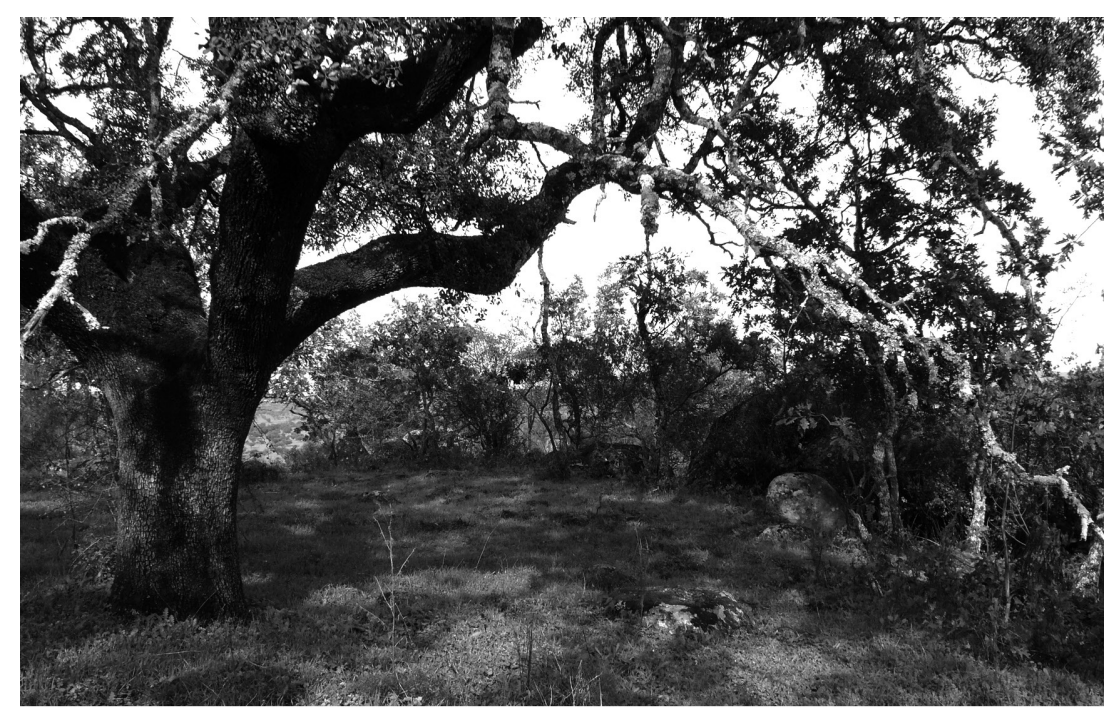

FIG. 5 - Plataforma correspondente à área de achado dos discos.

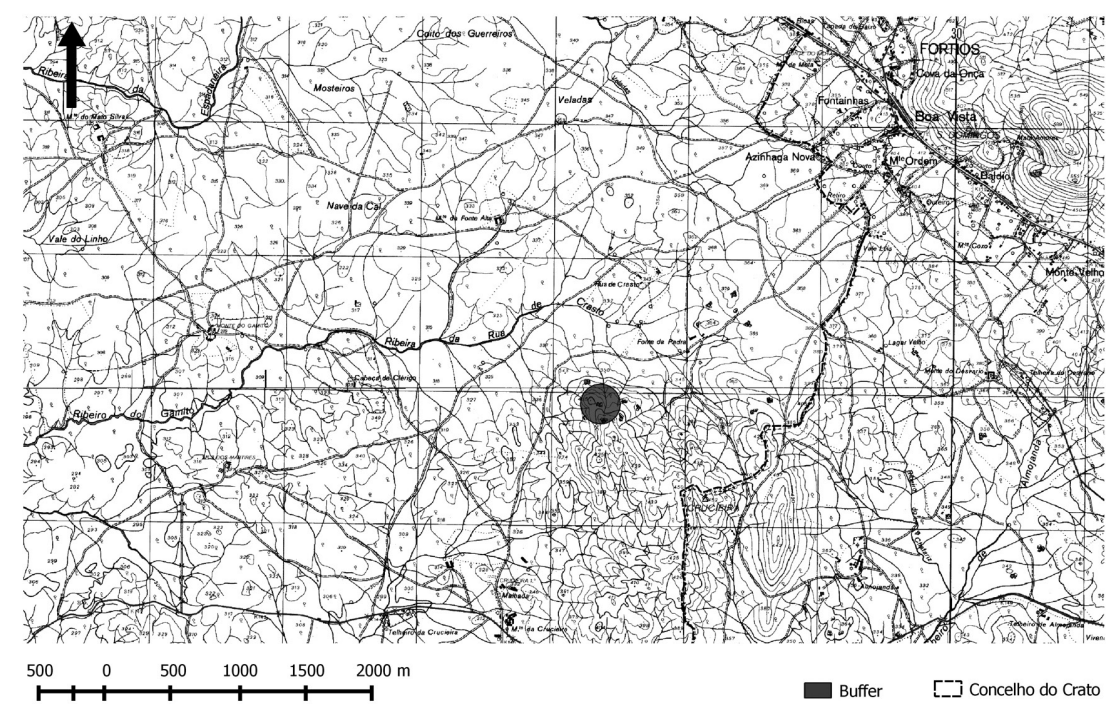

Fig. 6 - Local de achado dos discos

(Carta Militar de Portugal, 1: 25 000, folhas 347, Fortios e 359, Portalegre). 


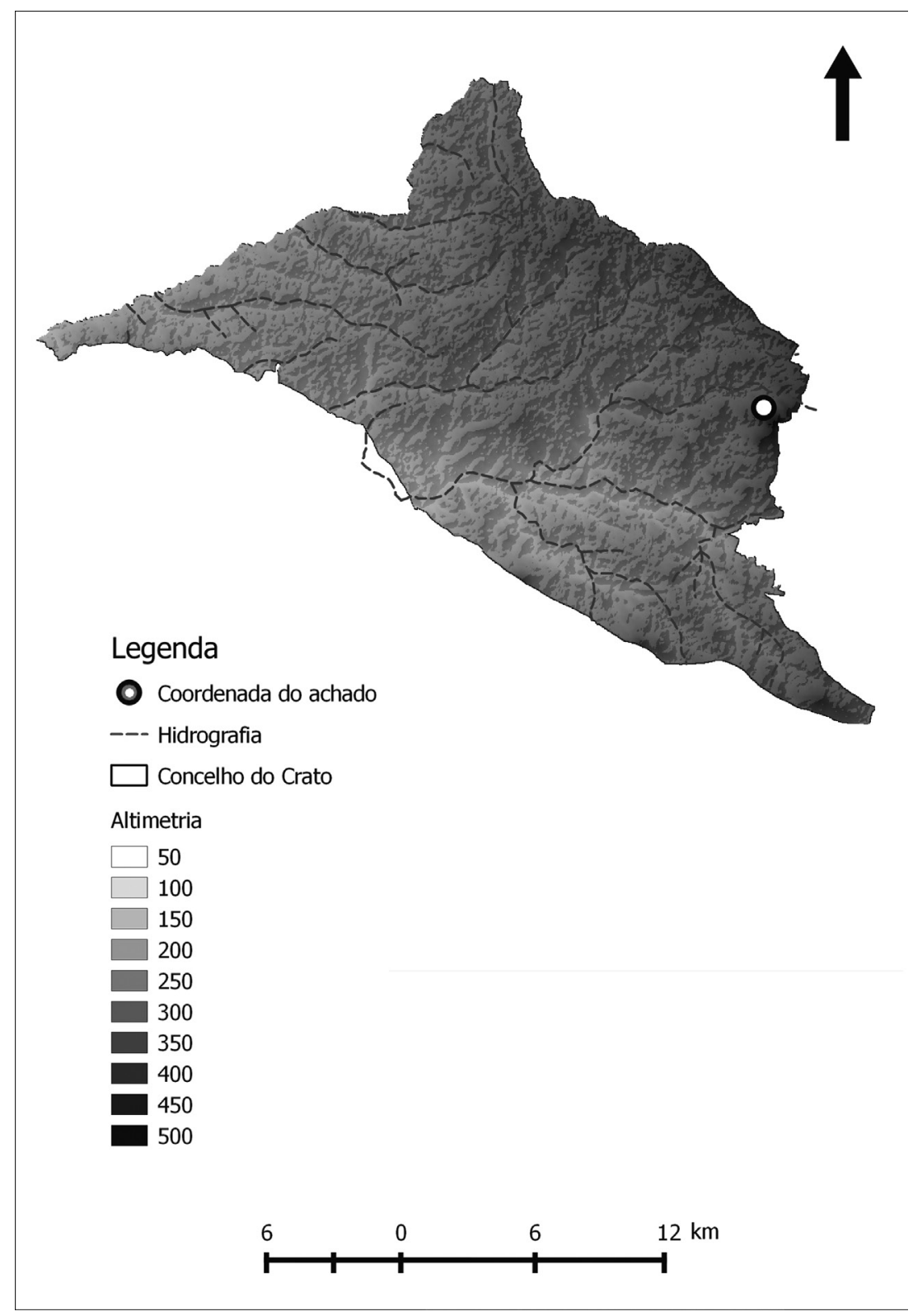

Fig. 7 - Localização do achado no concelho do Crato. 


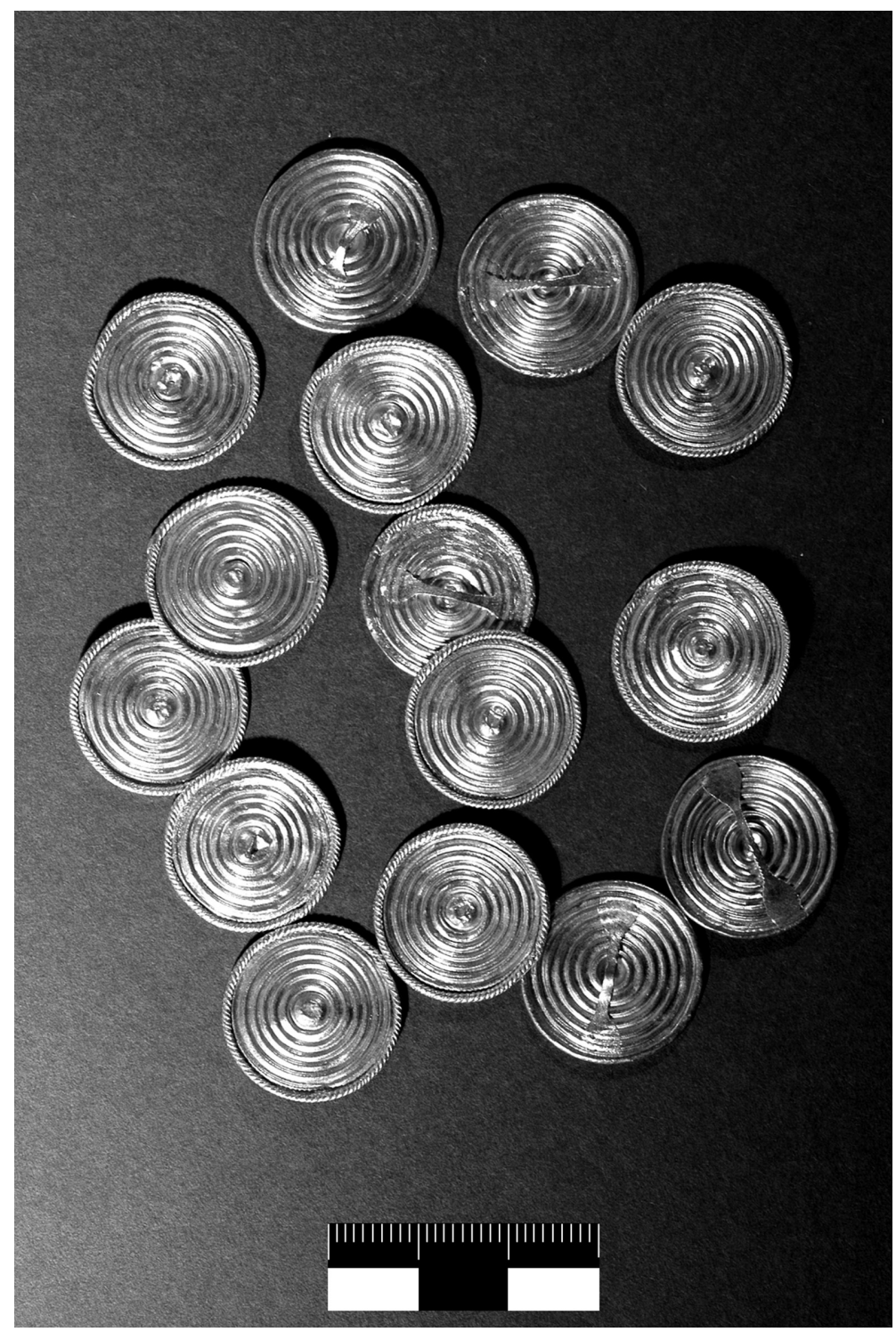

FIG. 8 - Discos pertencentes ao Instituto de Arqueologia (Coimbra). 

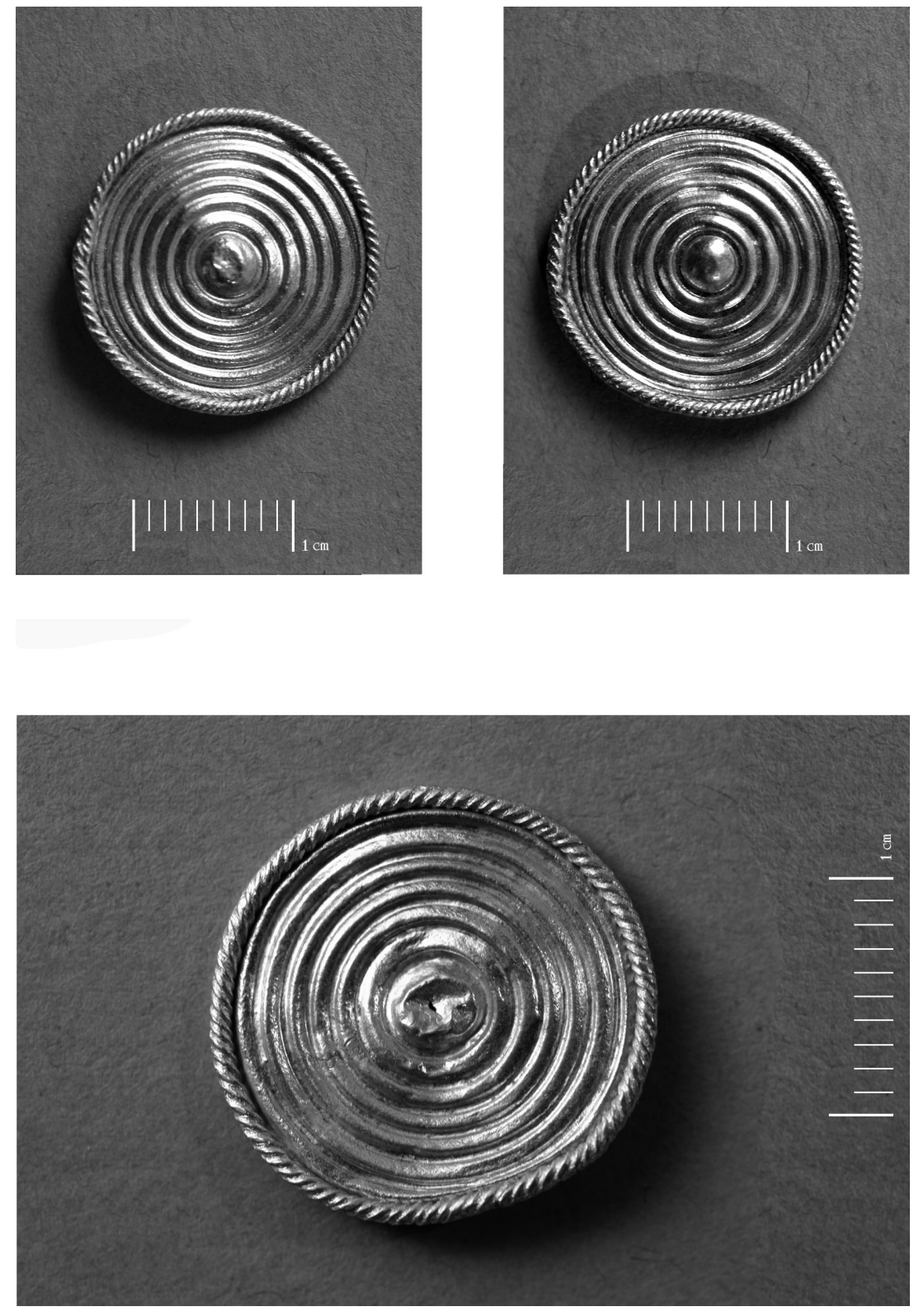

Fig. 9 - Discos do Instituto de Arqueologia (Coimbra) observando-se pequenas diferenças a nivel da conservação. 


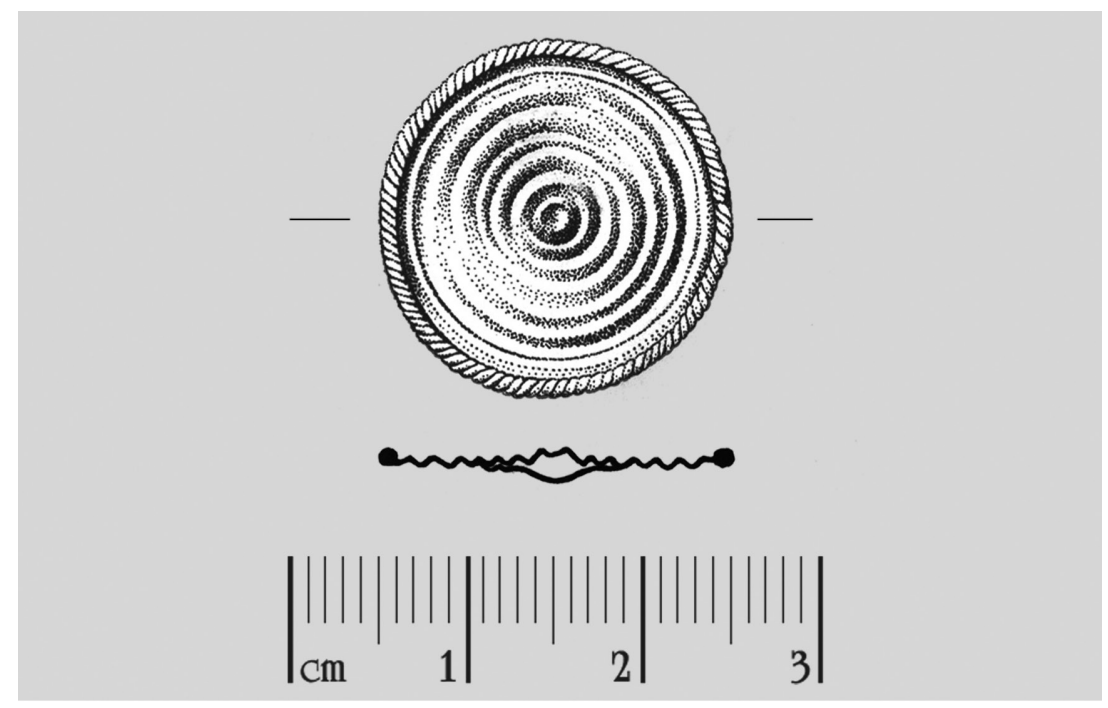

FIG. 10 -Disco Iarq. 1.

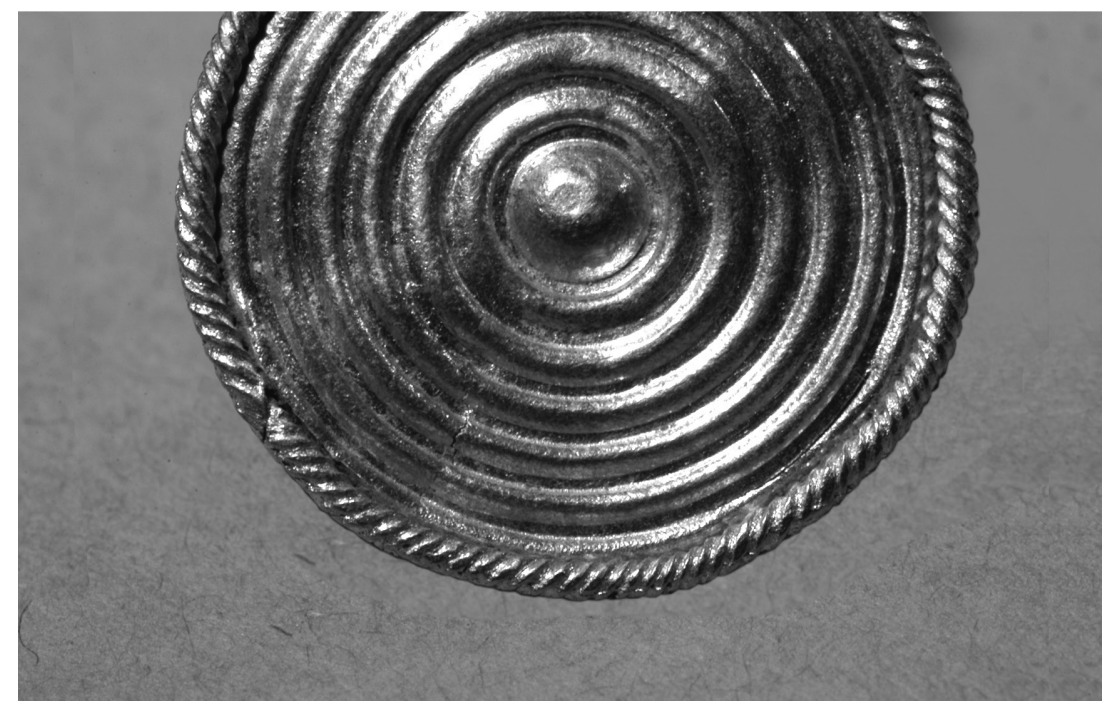

FIG. 11 - Pormenor da decoração do arame torcido e justaposição das respectivas extremidades. 

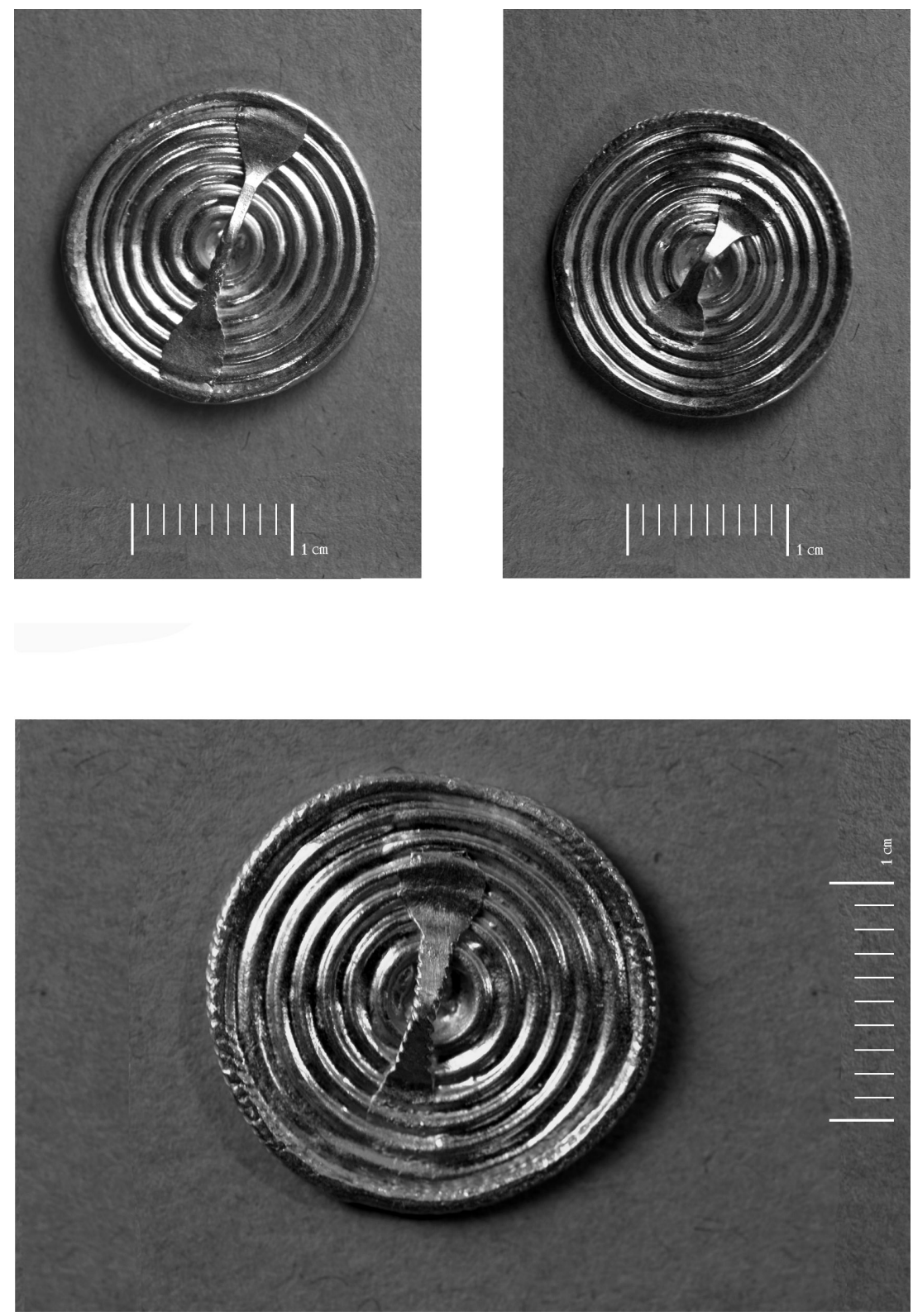

FIG. 12 - Diversas soluções de presilhas (curtas e longas, lisas e decoradas). 


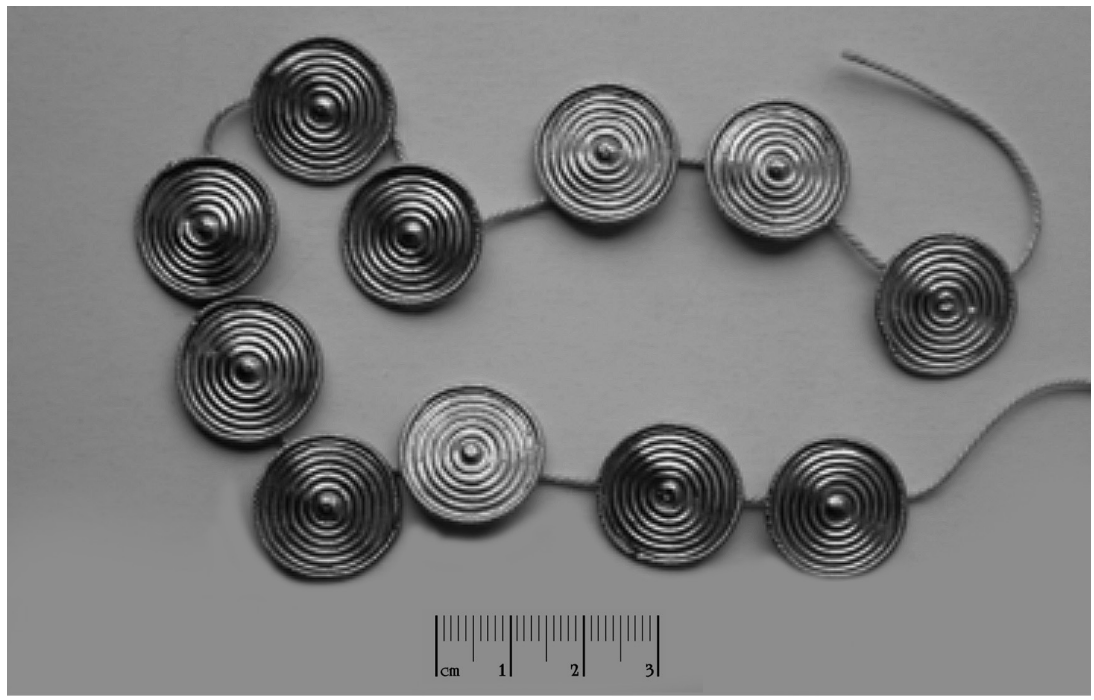

FIg. 13 - Discos pertencentes a colecção privada (J. C. Azeredo e família).

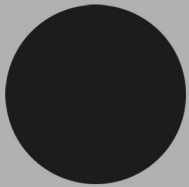

Fortios

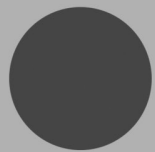

Outeiro da Cabeça

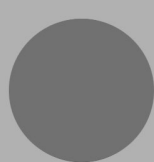

Baião

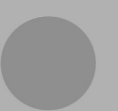

Castro de Ratinhos

El Carambolo

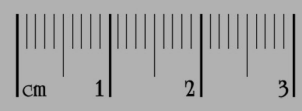

Fig. 14 - Comparação entre os diâmetros dos discos de distintos conjuntos. 


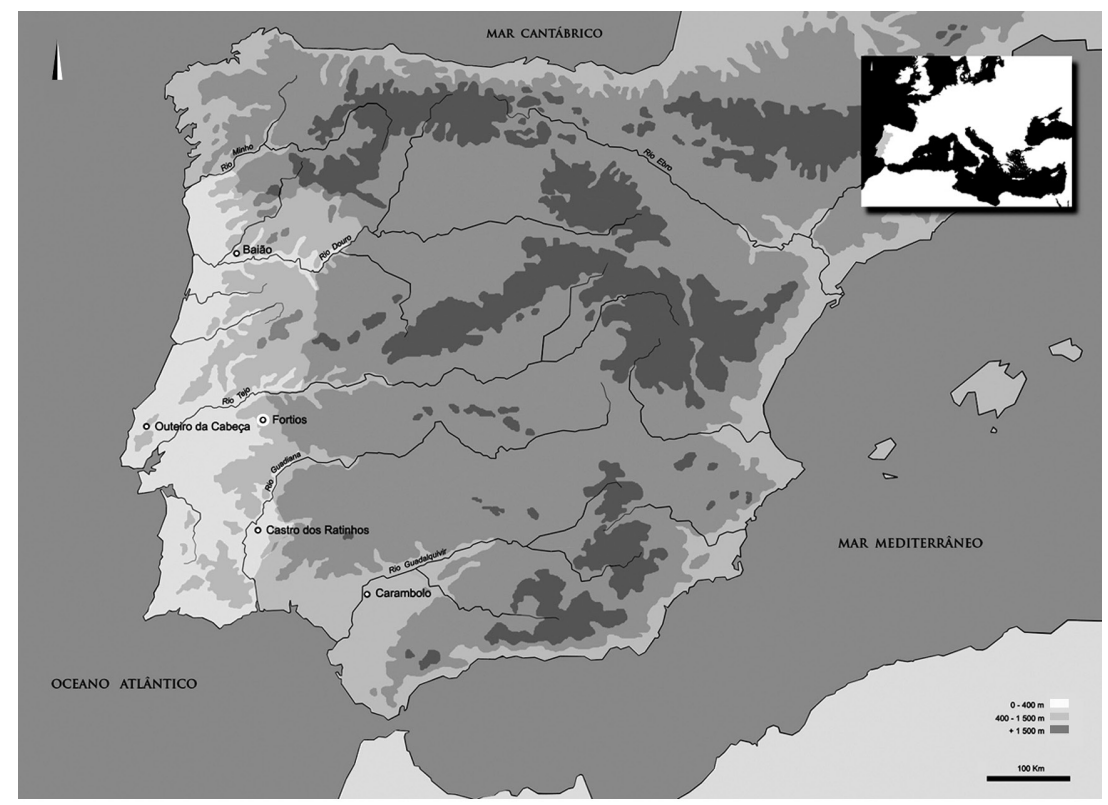

FIG. 15 - Localização dos achados dos discos de Fortios (Portalegre), Outeiro da Cabeça (Torres Vedras), Castro dos Ratinhos (Moura), El Carambolo (Sevilha) e Baião (Porto).

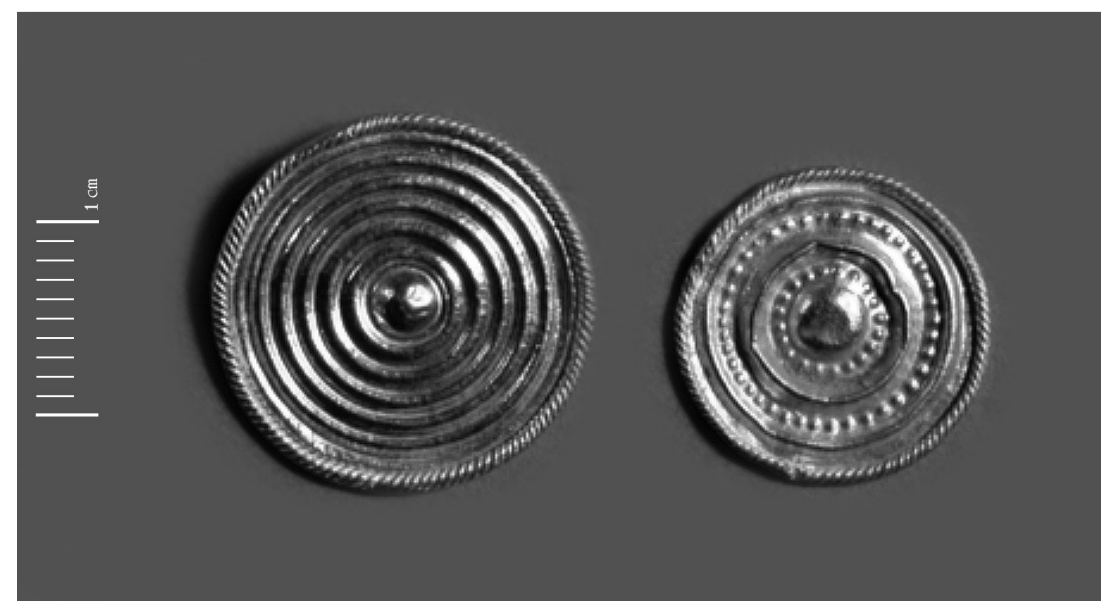

FIG. 16 - Comparação entre um disco de Fortios (à esquerda) e um disco do Outeiro da Cabeça (à direita). 


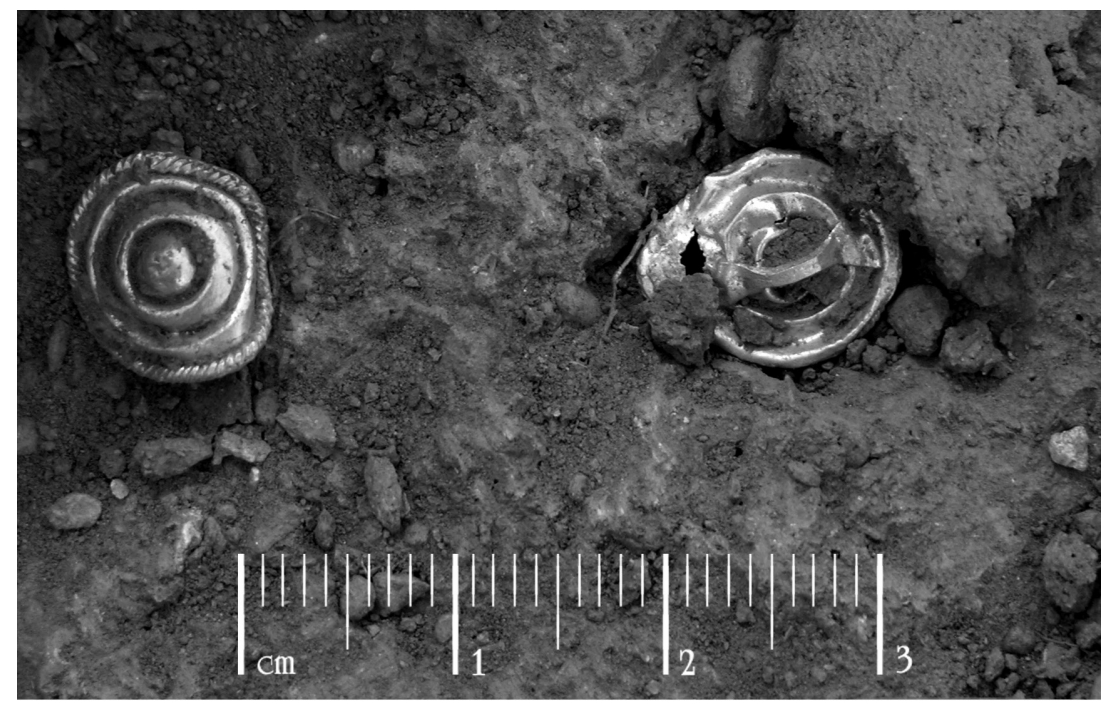

FIG. 17 - Dois dos discos do Castro dos Ratinhos no momento do seu achado, observando-se no canto superior direito o negativo de tecido impresso na terra (seg. Luis Berrocal-Rangel).

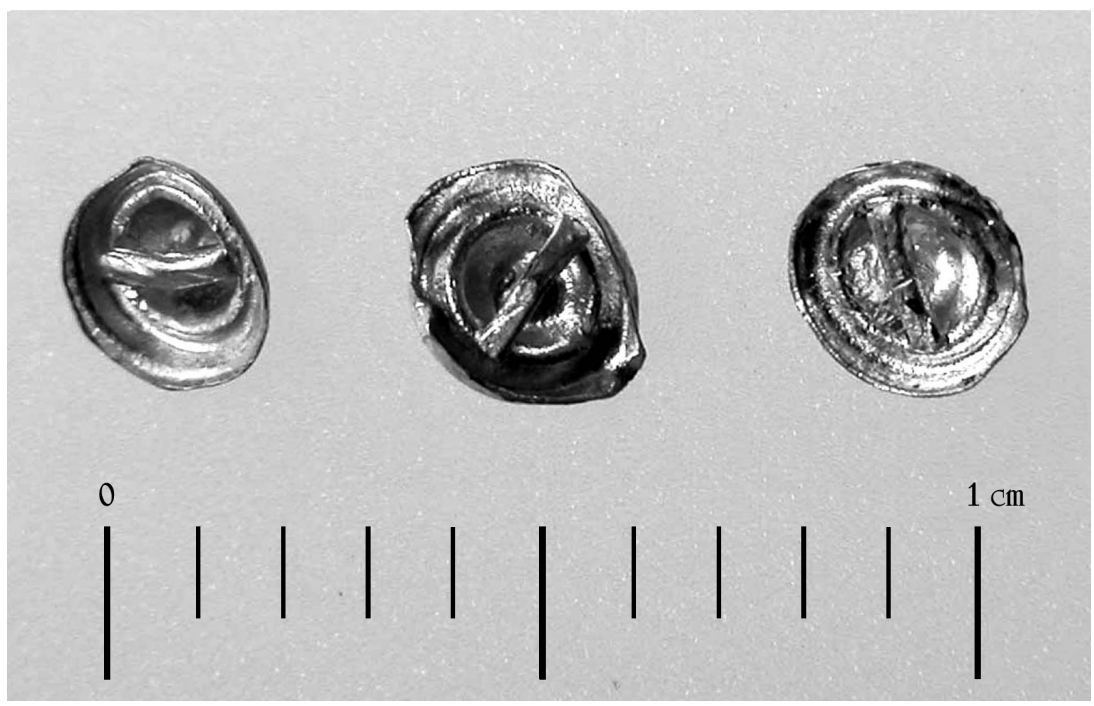

Fig. 18 - Botões de El Carambolo. 


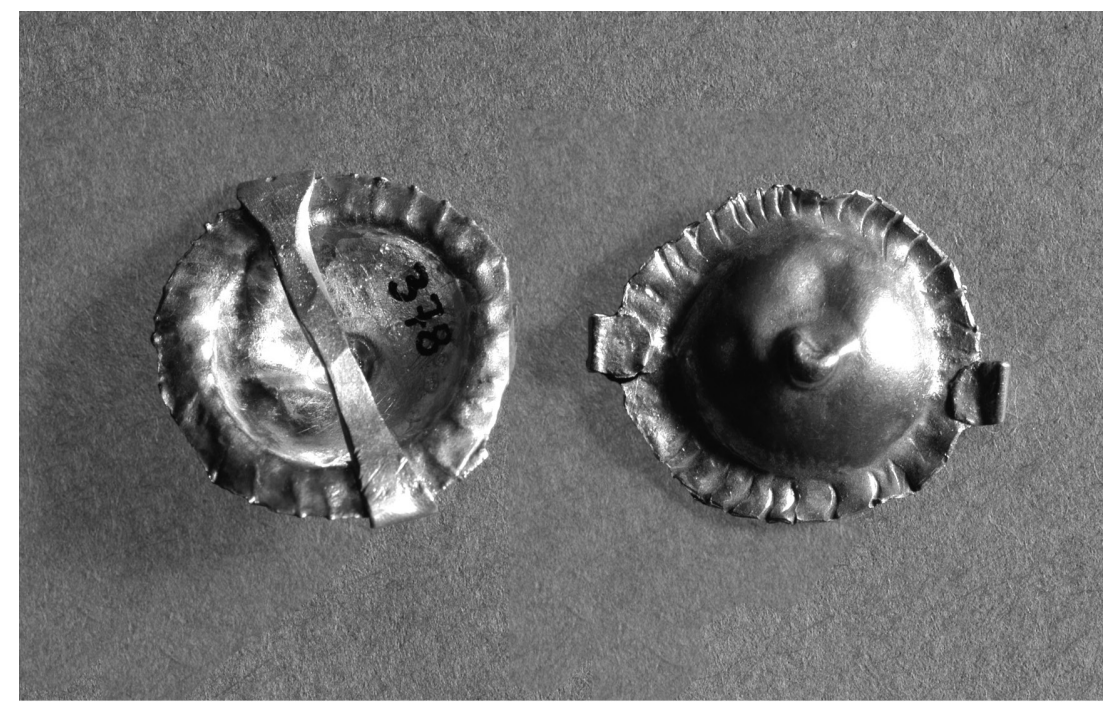

Fig. 19 - Reverso e anverso de uma das aplicações de Baião, observando-se a forma cónica e a fixação da presilha dobrada sobre o anverso.

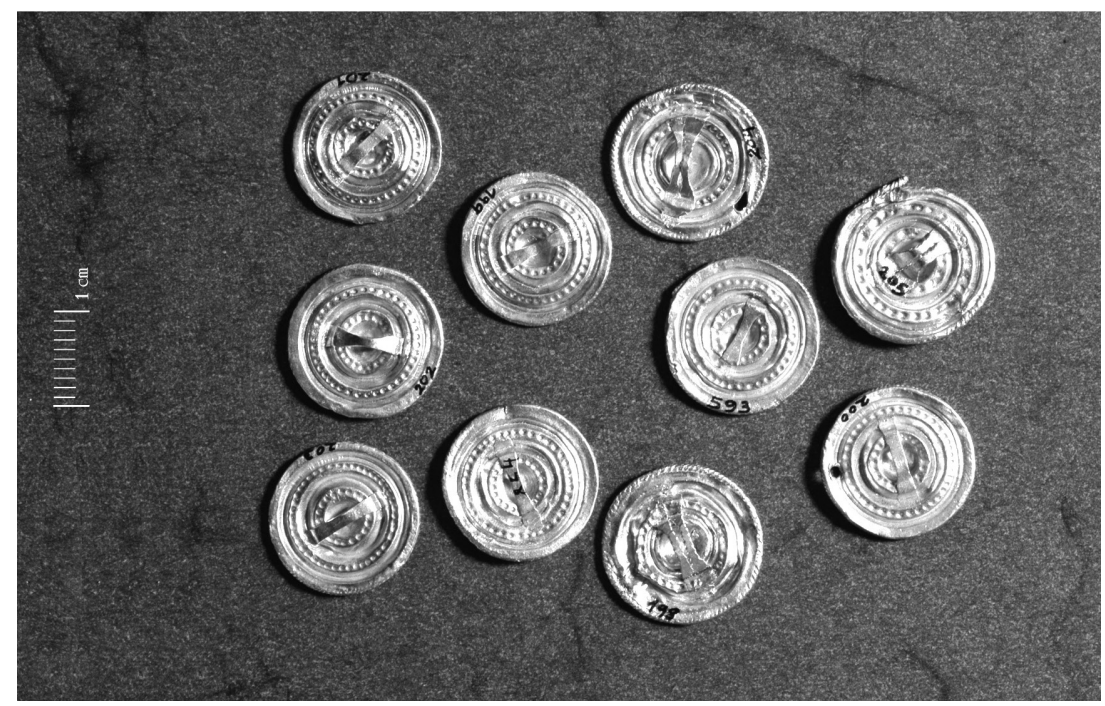

FIG. 20 - Reverso dos discos do Outeiro da Cabeça, observando-se em alguns deles presilhas duplas. 


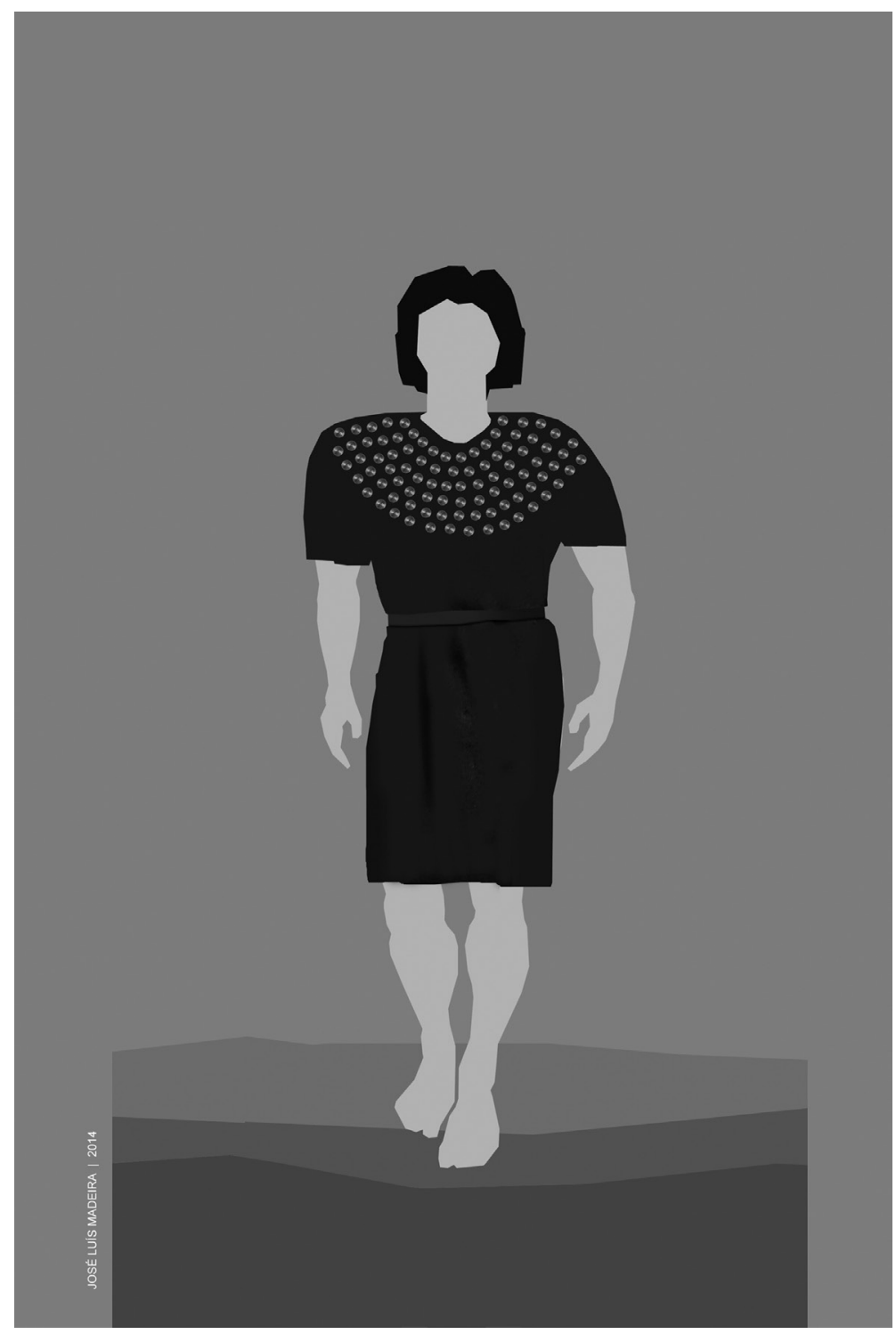

FIG. 21 - Interpretação livre da aplicação dos discos de Fortios sobre vestuário de prestígio. 